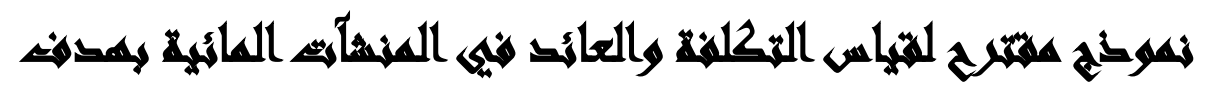

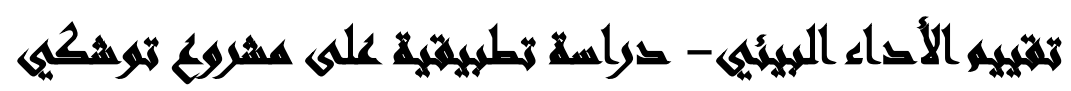

[rr]

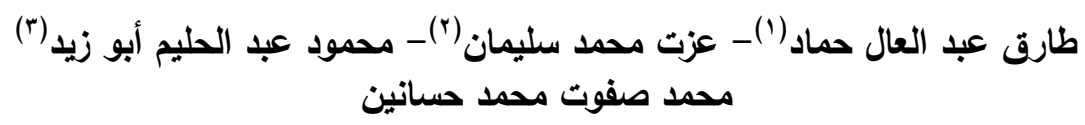

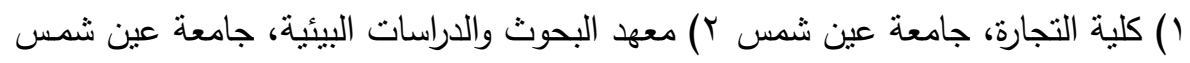

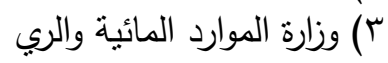

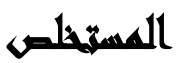

رغم أن البيئة قد استمرت بانزانها الإعجازي بقدرة الله تعالى فقد جاء الإنسان متعددا

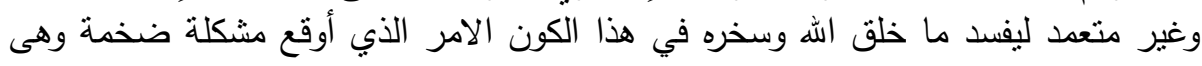

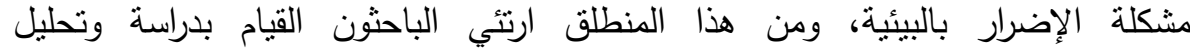

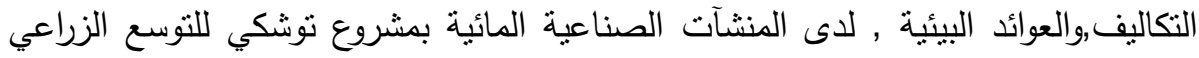

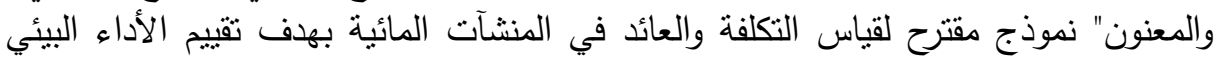

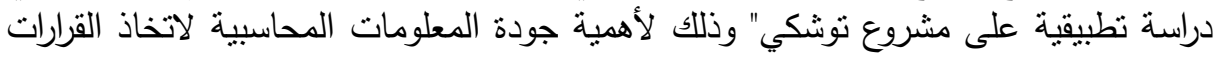

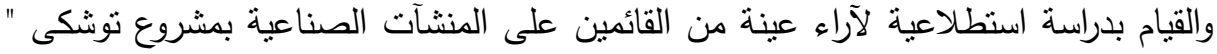

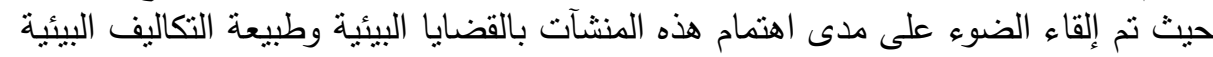

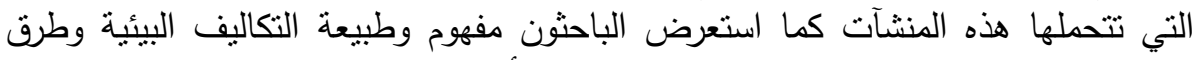

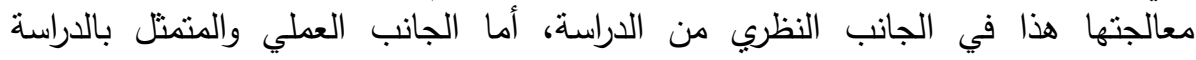

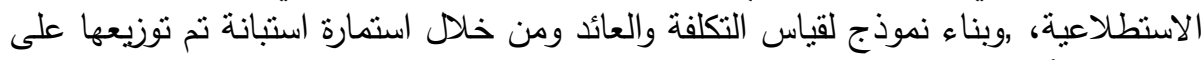

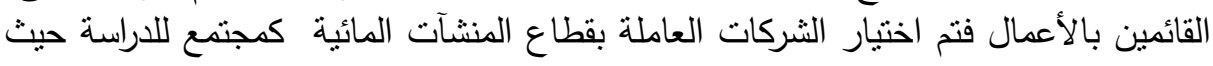

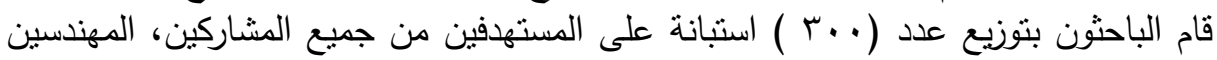

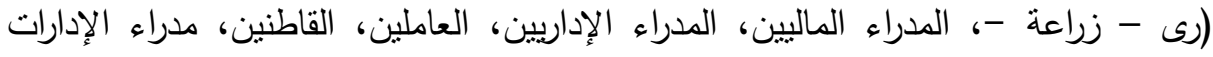

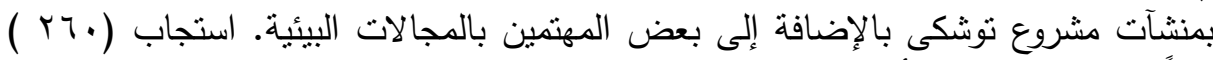

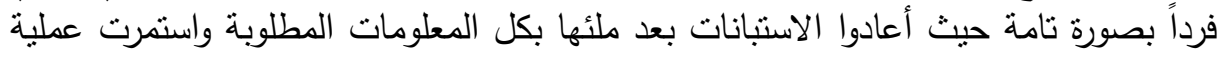

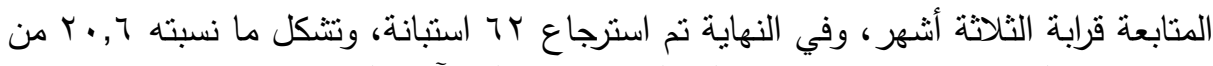

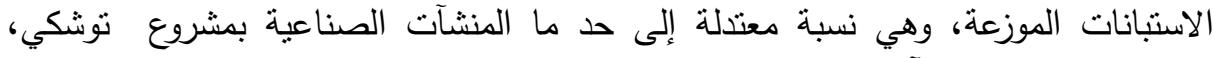

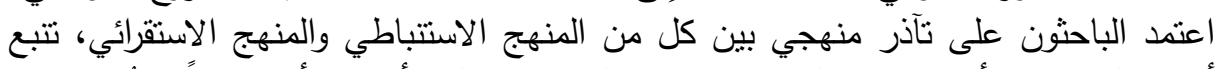

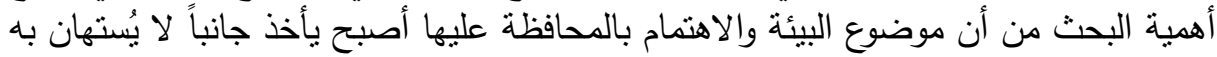

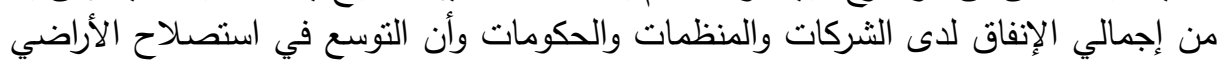

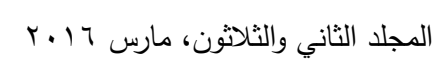


الجديدة من اجل التتمية الثاملة أصبحت تأخذ دوراً مهماً في اقتصاديات البلاد و يتمثل هدف

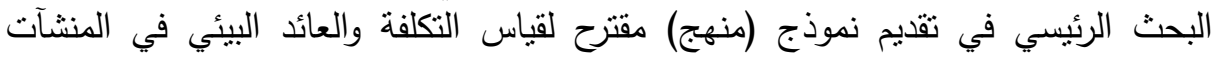

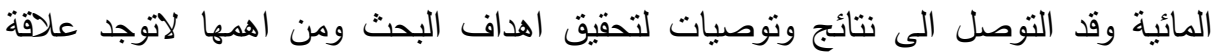

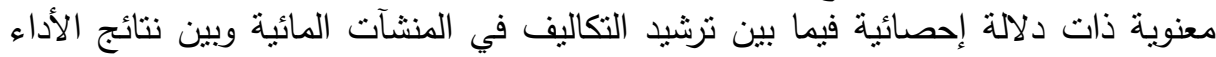

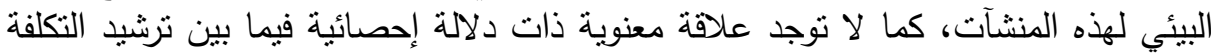

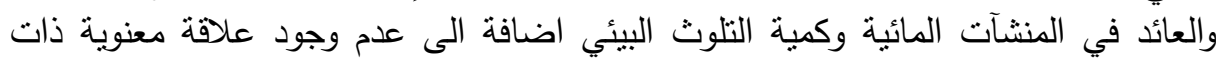

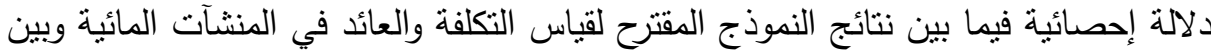

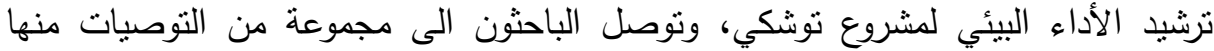

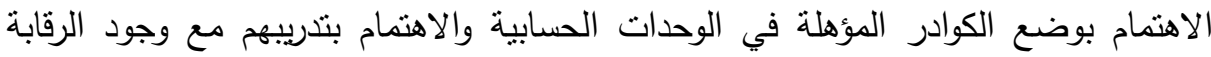

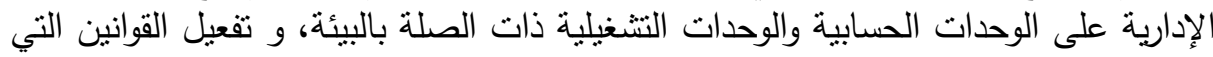

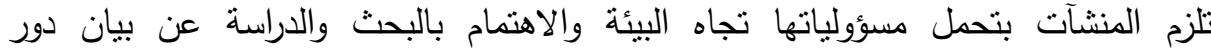

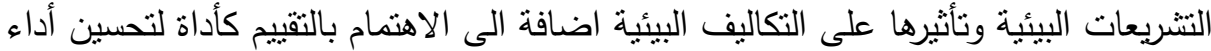

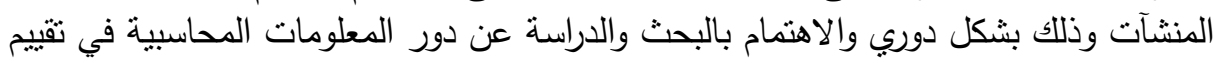

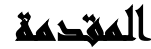

أصبحت البيئة أحد الاتجاهات المهمة التي حظيت باهتمام كبير في السنوات الأخيرة في

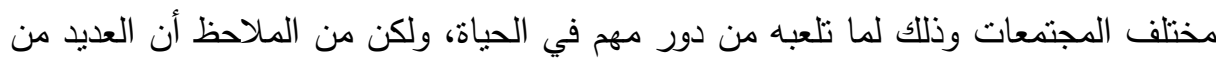

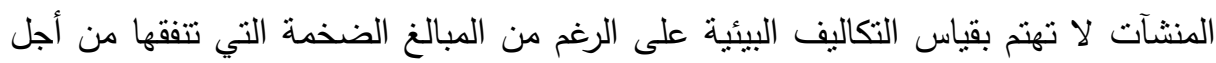

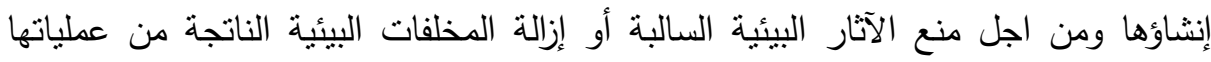

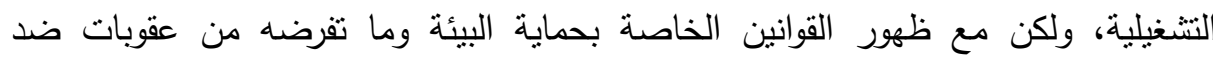

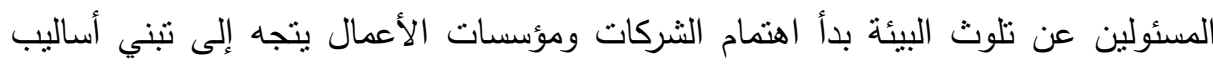

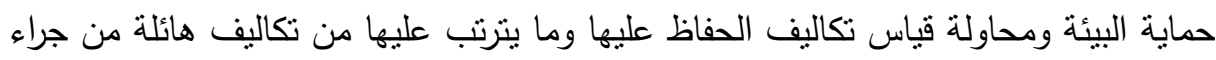
عدم الالتزام بقوانين ومعايير الحفاظ على البيئة وحمايتها، وعليه فقد أصبحت الأمور البيئية

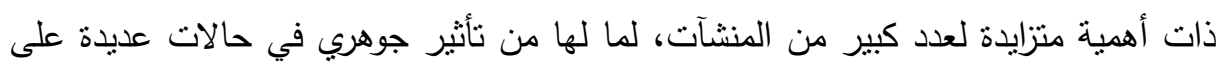

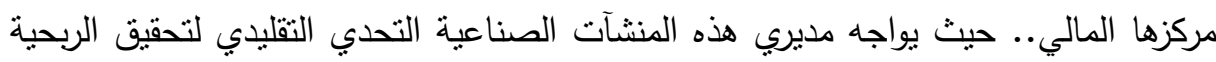
والعائد المرضي والتحدي الممثل في مسئوليتها عن سلوك بيئي مناسب، ولما كان للمحاسبة

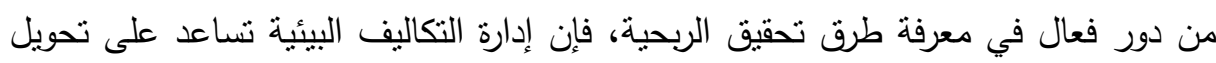
456

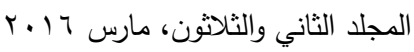


مفهوم الإدارة البيئية إلى آليات لتحقيق تطور وارتقاء المنثآت بما لها من دور فعال في القرارات الإدارية، وذللك مع تزايد المنافسة وانتشار تقنيات الاتصالات والمعلومات والاهتمام

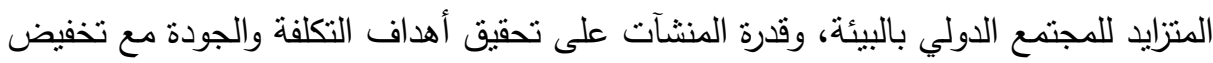

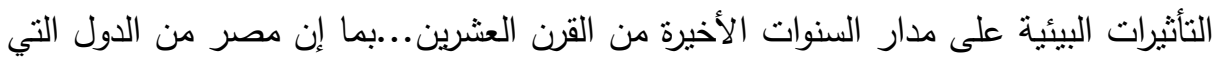

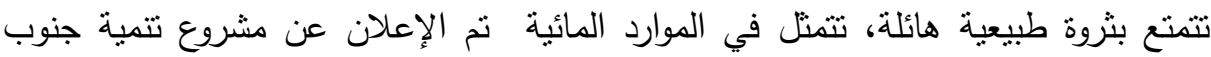

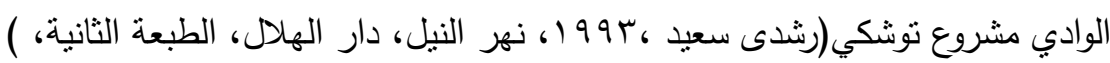

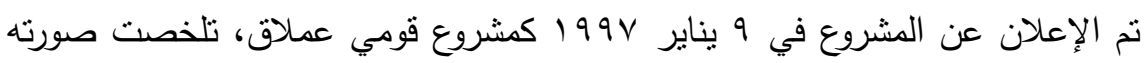

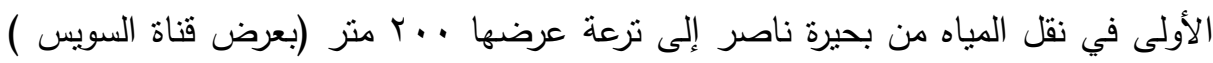

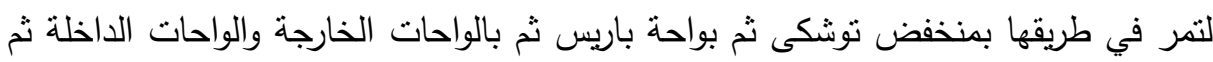

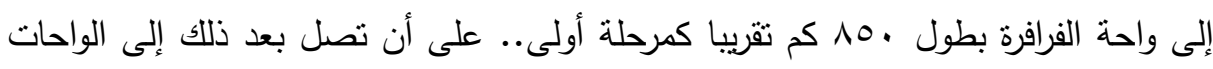
البحرية وتستمر فى طريقها لكى تصب فى النهاية بمنخفض القطارة... وتراوحت تكلفة

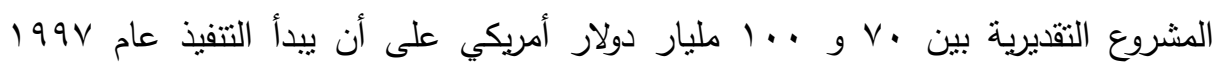

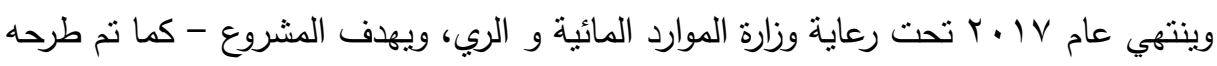
- إلى خلق Y,_, مليون فرصة عمل جديدة وتوطين 17 مليون مواطن وأسرهم (عبد القادر

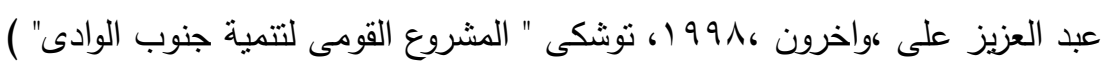
ورأى الخبراء غير الحكوميين أن المشروع على هذه الصورة لا يصلح لعدة أسباب أهمها:

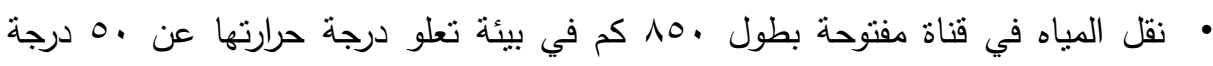

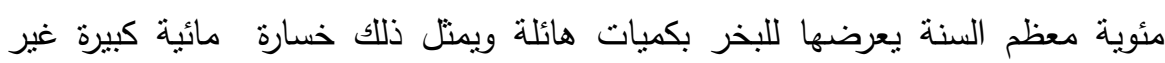
محسوبة . منوبه معظم

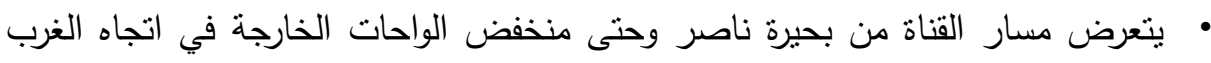
إلى الغمر بالرمال حيث أنه يثقاطع مع أكثر من بـ بـ خطا من خطوط الكثبان الرملية

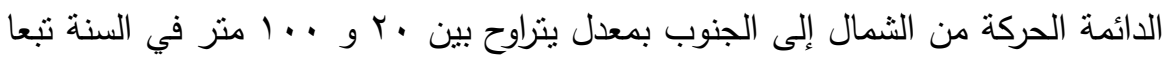

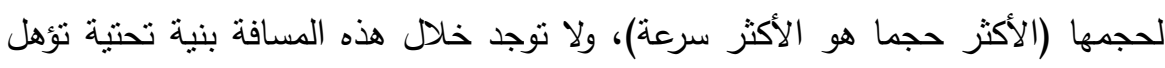
لإمكان تفادى حركة الكثبان الرملية.

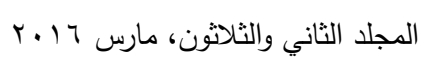


•وهو الأهم، أن إيصال كمية كبيرة من المياه إلى الواحات الخارجة والداخلة والفرافرة بزيد

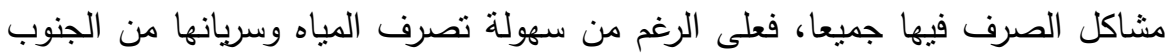

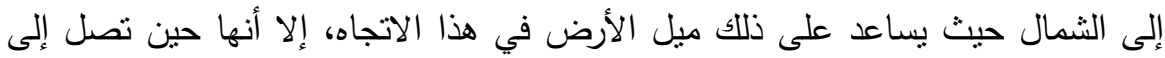
تلك الواحات التي توجد في منخفضات طبوغرافية فإنها تبقى بداخلها وتتبخر وتزيد من

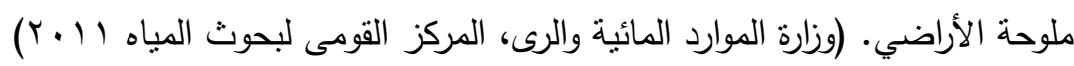

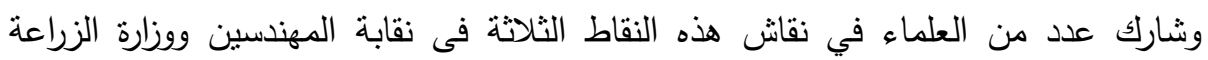

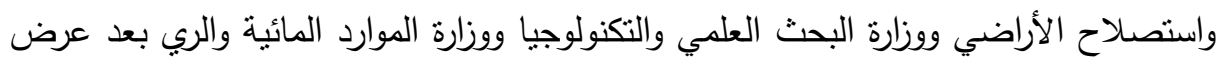
للمؤشرات العلمية التي تتبت عدم جدوى القناة المزمع إنثاؤها غربا من منخفض توشيكي. وعلى ذلك غيرت الحكومة خطتها وانحسر طول القناة من •10 كم إلى TV كم ، والحديث عن منطقة توشكى من الناحية الجيولوجية أن منخفض نوشكى كانت تصب في فيه أودية عديدة تتبع فى المرتفعات إلى الغرب والجنوب الغربي أثناء عصور ممطرة فى الماضي، حيث كانت

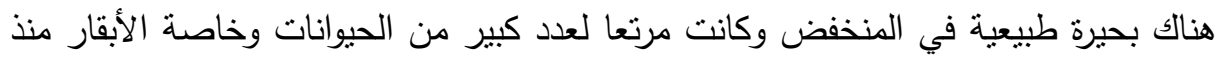

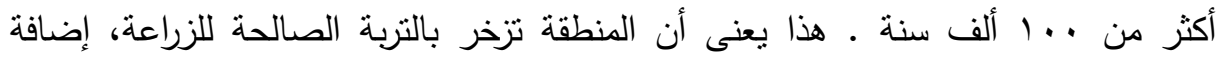
لتواجد بعض المياه الجوفية ... إذن فإن إمكانبة استصلاح الاراضى في المنخفض وحوله مبنية على علم ومعرفة بطبيعة الأرض وتاريخها. ( عبد الرحمن شلبى، الجوانب الفنية والاقتصادية والبيئية لمشروعات التتمية في الوادى الجديد، مجلة طنطا للبيئة، عدد خاص عن الاصن

ومشروع توشكي في صورته الحالية، كما طرحته الحكومة فى صورته الأولى تقريبا، التي

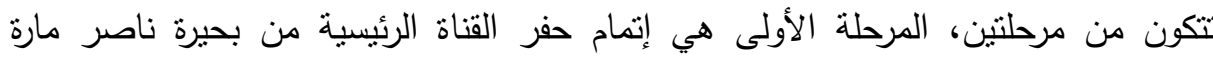
بمنخفض توشكى إلى أن تصل إلى واحة باريس شمالا، وأن المرحلة الثانية تتمثل فى نكملة الثنة

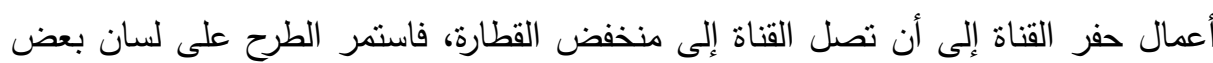
المحاضرين ببعض المؤتمرات حتى وقت قربب بنفس الصورة الأولى دون متابعة للتعديلات

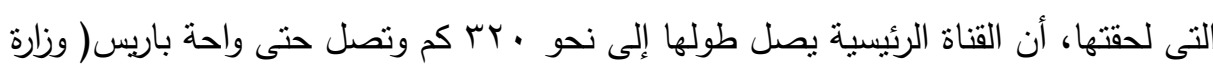

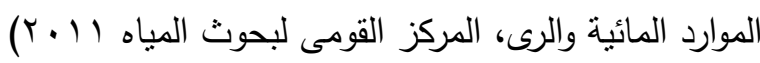




\section{الصورة الحالية لمشروع توشكي:}

بحيرة ناصر بالركن يمتد منها خور توشكا ومفيض توشكا الطبيعي الذي يتقاطع مع أحد فروع القناة الرئيسية (قناة الثيخ زايد)، مكونات المشروع الرئيسية وهى محطة الطلمبات الرئيسية على بحيرة ناصر، التي تضخ المياه بقناة الثيخ زايد، التي تتفرع إلى فرعين، يتقرع كل منهما إلى فرعين آخرين، لري الأراضي القابلة للاستصلاح والزراعة ومساحتها الإجمالية تبلغ •عه ألف فدان • وتخدم منطقة نوشكي شبكة طرق ممهدة، تبدأ بطريق من محطة الطلمبات الرئيسية على بحيرة ناصر، ليتفرع بعد ذلك إلى أربعة طرق إلى مدينة أسوان وإلى لى لهن أبو سمبل وإلى وادي حلفا وإلى العوينات لمئل مكونات المشروع الرئيسية محطة الطلمبات الرئيسية (المعروفة باسم محطة طلمبات مبارك وهى محطة عملاقة تم تصميمها بحيث تضمن استمرارية الضخ للقناة الرئيسية بالمشروع (منسوب سطح المياه بها .. r منز فوق منسوب سطح البحر) - عندما ينخفض مستوى

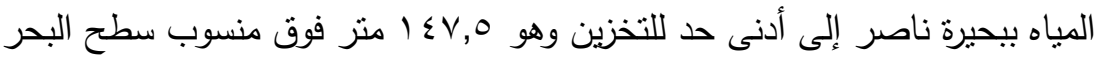

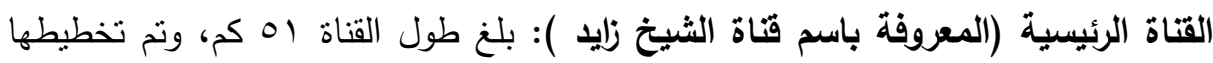

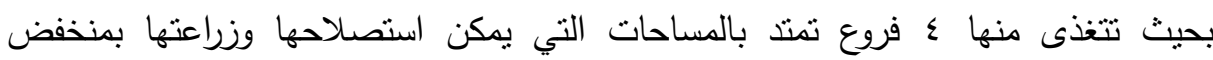

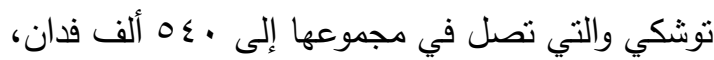

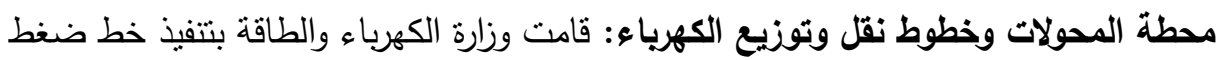

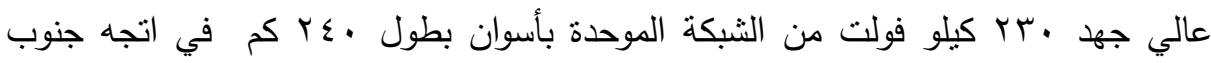
غرب السد العالي إلى محطة محولات مشروع توشكي ل| 1 كيلو فولت بقدرة ... ميجاوات ومحطة توزيع لتغذية محطة الطلمبات بقدرة م. r ميجاوات

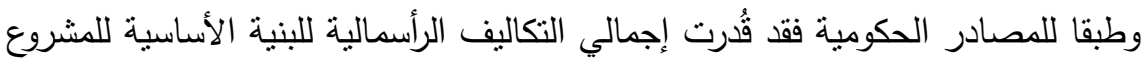

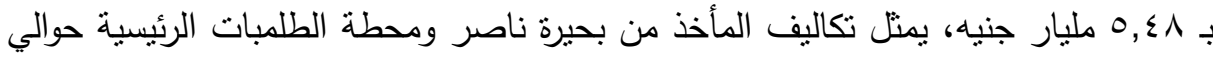

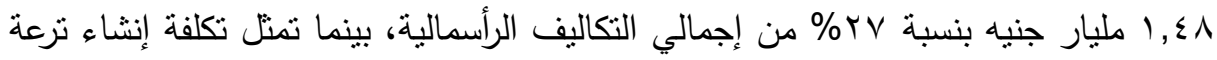

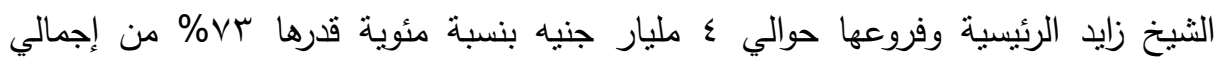

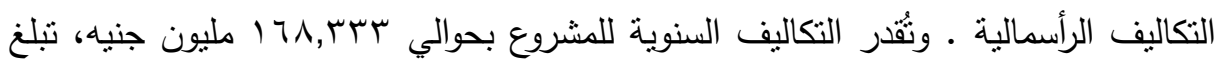

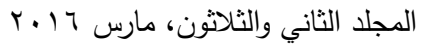


قيمة الأجور منها حوالي Y,V مليون جنيه، وقيمة المستلزمات السلعية والخدمية حوالي ماني

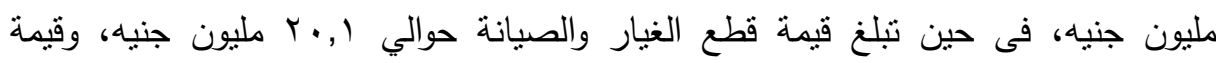

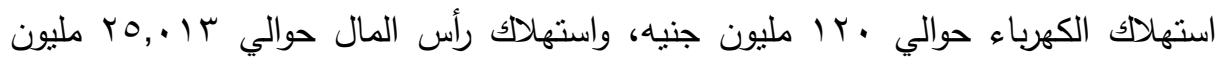

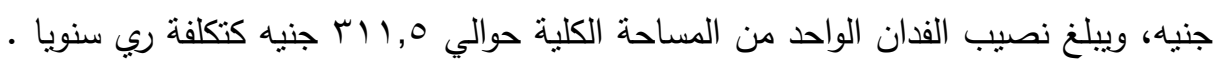
ويلاحظ أن تكلفة الطاقة الكهربائية تبلغ أكثر من • • من من إجمالى التكاليف السنوية. (وزارة الموارد المائية والرى - سابق الاشارة اليه).

\section{التراساهي المرجعية}

ا ـدراسة عادل حسن دشتي.، ؛ 1 ـ ب والمقدمة بعنوان نموذج مقترح للتكاليف البيئية وأثرها على القوائم المالية- دراسة ميدانية بالتطبيق على القطاع النفطي بلولة الكويت -دكتوراه- جامعة عين شمس- معه دراسات البحوث البيئية- العلوم الاقتصادية والقانونية والإدارية البيئية

أهداف الاراسة: تتمثل المشكلة الرئيسية للبحث في: "وجود أوجه قصور في نظم وأساليب

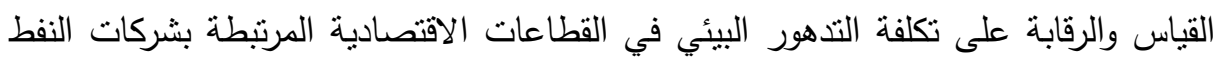
الكويتي- شركات البترول- وبصفة خاصة عند تحديد تكلفة التدهور البيئي في الثركات

•يتمنل اهتمام الثركات النفطية بالقضايا البيئية من خلال برامج التوعية البيئية للموظفين. •أهم أسباب عدم اهتمام بعض هذه الثركات بالقضايا البيئية هي عدم توافر الموارد المالية.

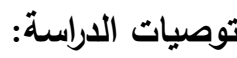
•ضرورة اهتمام الإدارة العليا الثركات النفطية بدولة الكويت بتكثيف جهودها نحو مكافحة التلوث الناتج عن الأبخرة والغازات وتلوث المياه والمخلفات الصلبة. •ضرورة زيادة الوعي البيئي لهؤلاء العاملين • 
•تخصيص الموارد المالية اللازمة لحماية البيئة من قبل إدارات المنشآت النفطية

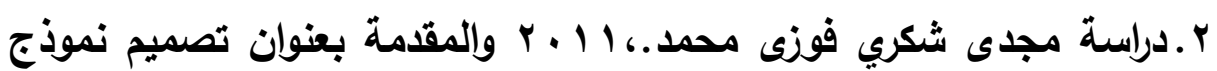
مقترح لقياس تكلفة التدهور البيئي ببعض قطاعات التثييذ والبناء دكتوراه- جامعة عين شمس - معهد دراسات البيئية - الاقتصاد والقانون

\section{والتنمية الادارية البيئية}

أهداف الدراسة: تقييم نظم التكاليف بشركات المقاولات بهدف تحديد عناصر تكلفة التدهور

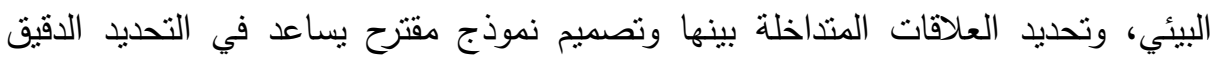
لتكلفة التدهور البيئي في شركات المقاولات. نتائج الدراسة: أكدت النتائج على وجود نأثير مباشر لجميع المتغيرات المستقلة المتمنلة في مقومات النظام المحاسبي في شركات المقاولات والإفصاح المحاسبي البيئي في شركات المقاولات، مشاكل قياس تكلفة التذهور البيئي، على القيمة المضافة الاقتصادية الحقيقية توصيات الدراسة: • إتباع أسلوب تكاليف الإحلال ويقصد بها تكلفة إعادة الموارد الطبيعية. • استخدام أسلوب التكاليف الوقائية البيئية للحفاظ على الأصول البيئية،

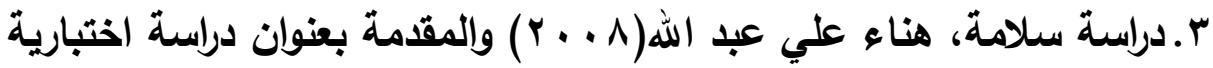
مقارنة لمعايير المحاسبة عن الاداء البئي في منشآت الاعمال المصرية ماجستير - جامعة بنها - كلية التجارة - محاسبة

أهداف الاراسة: القيام بدراسة اختبارية مقارنة لمعايير المحاسبة عن الأداء البيئي في منشآت الأعمال المصرية وذلك من خلال: 1 - توضيح مفهوم وابعاد الاداء البيئي وأهميته وانعكاساته على المحاسبة r - توضيح مفهوم ومنطلبات القياس المحاسبي للأداء البيئي r- توضيح مشكلات واجراءات القياس المحاسبي للأداء البيئي . 
نتائج الاراسة : زيادة الاستثمارات المصرية في الأوراق المالية، زيادة الاستثمارات الأجنبية في الثركة، زيادة المركز التنافسي للشركة في أسواق المال العالمية والمصرية، تكوين سمعة طيبة الاوراف

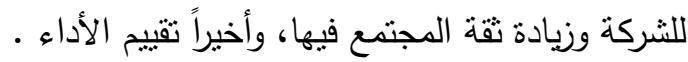
توصيات الاراسة: • ضرورة زيادة الوعي البيئي والعمل على نشره لدى منشآت الأعمال

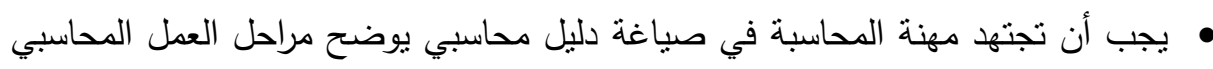
البيئي بداية من مرحلة القياس وحتى مرحلة الإفصاح وإعداد التقارير

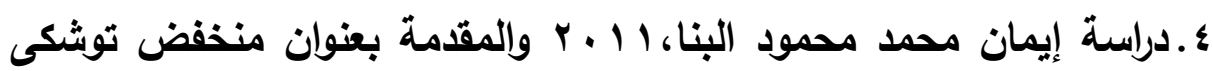
دراسة في الجيومورفولوجيا التطبيقية باستخدام نظم المعلومات الجغرافية

والاستثعار عن بعد -ماجستير - جامعة بنها - كلية الآداب - الجغرافيا

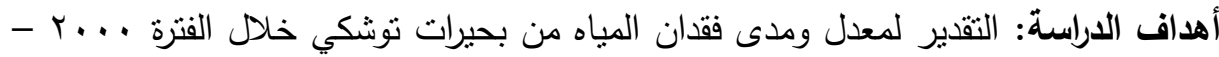

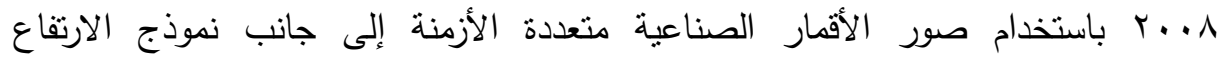
(الرقمي(ماركا) نتائج الاراسة: ناقش الجيومورفولوجيا وأظهر الاسنطلاع أن هناك علاقة قوية بين إمكانية التنمية العامة في مستقبل وطبيعة السطح وهناك تأثنر مباشر من الماء من نوشكي البحيرات على النشاط الزراعي والسكان توصيات الاراسة: تفعيل دور العوامل الجيوبيئية لتعظيم العائد من سياسات التتمية الاقليمية ه.دراسة أبو زيد، طلعت أحمد إبراهيم 11 ـr , والمقدمة بعنوان دراسة استكثافية لبعض العوامل المؤثرة على تبنى زلاع منطقة توشكى لبعض الممارسات الزراعية الحديثة - ماجستير - جامعة المنيا - كلية الزراعة الاقتصاد الزراعي أهداف الدراسة: استكثاف بعض العوامل المؤثرة علي تبني زراع منطقة نوشكي لبعض

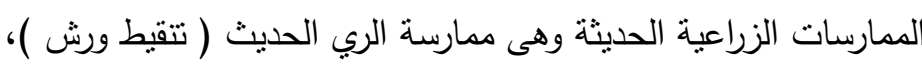


نتائج الداسة: تبين من النتائج أن جميع المزارعين المبحوثين أفراد عينة هذا البحث من

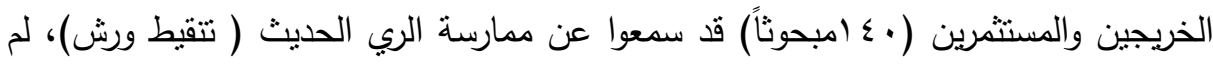
ينفوا هذه الممارسة مطلقاً توصيات الدراسة: تحليل الوضع الانتاجي للمحصول، والاراضي الجديدة خاصة ،بما يتضمنه

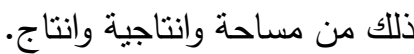

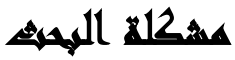

يرى الباحثون أنه بعد ازدهار إقامة المنشآت المائية لخدمة مشروع نوشكي من محطة

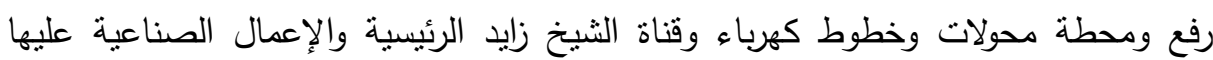

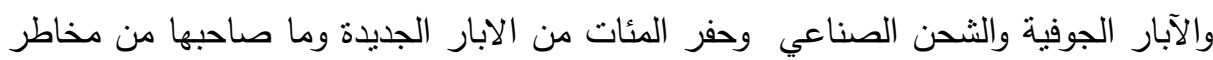

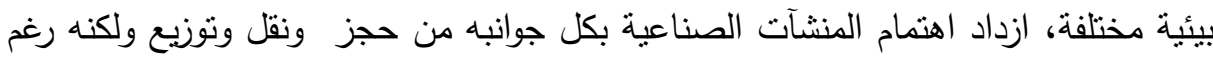

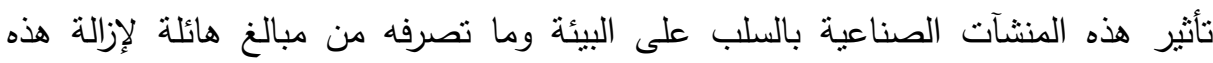

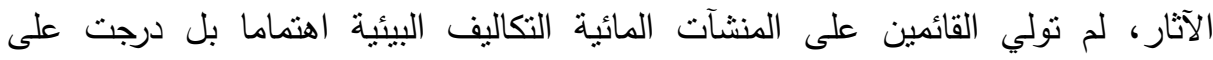

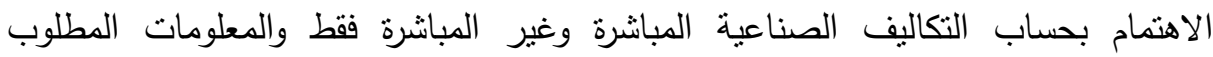

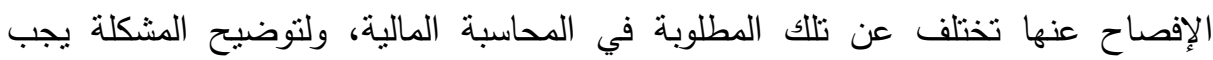

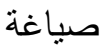

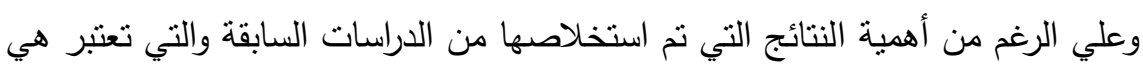

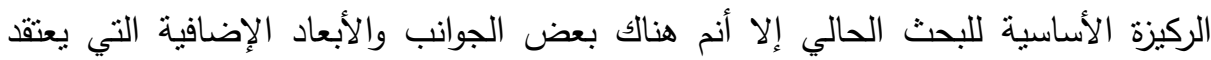
الباحثون أن الدراسات السابقة لم تغطها والتي سوف يحاول الباحثون تتاولها بالدراسة والنحليل والاختبار الميداني ومن أهم الجوانب ما يلي: الباني: ماختبار العلاقة ميدانيا بين مدخل قياس التكلفة والعائد للمنشآت المائية وتقييم الاداء البيئي

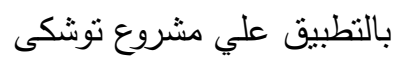


• سوف يستخدم الباحثون مجموعة مقترحة ومتكاملة من مؤشرات القياس في مجالي التكلفة

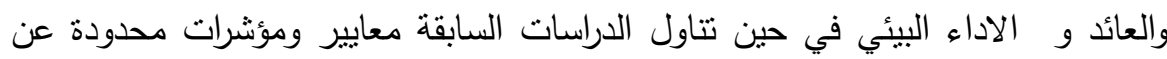
القباس في بيئة اخرى. - مان. • سوف يحاول الباحثون التوصل إلي إطار وروية لتطوير ترشيد القرارات في إطار استخدام مدخل القياس فى المشروع. بناء نموذج تجريبي لقياس التكلفة والعائد.

\section{أهمية الهيهي}

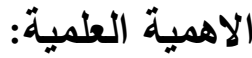

تتبع أهمية البحث من أن موضوع البيئة والاهتمام بالمحافظة عليها أصبح بأخذ جانباً لا

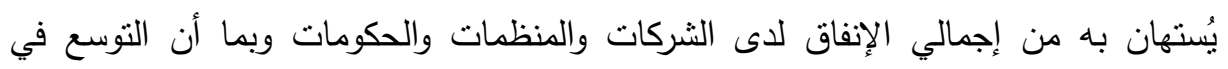

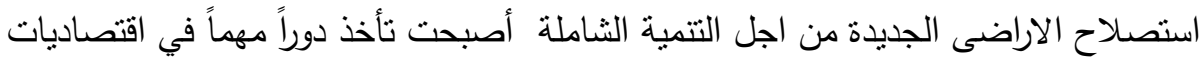

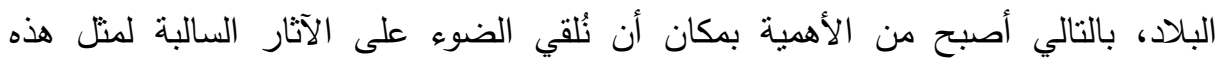

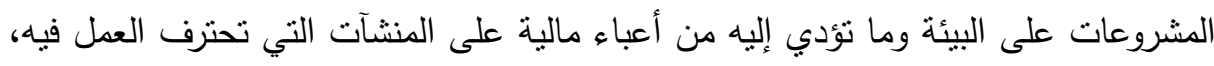

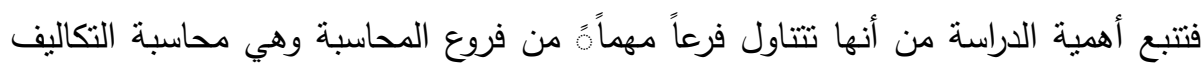

$$
\text { البيئية. }
$$

\section{الأهمية العملية}

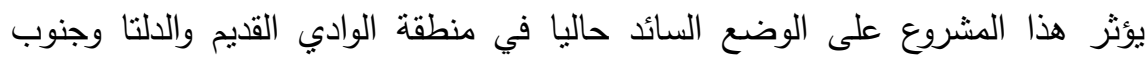

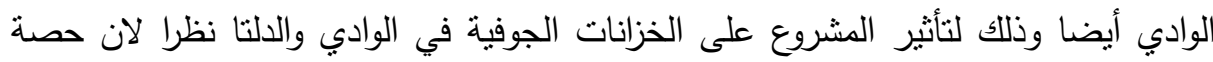
مصر من مياه النيل والمسحوبة خلف السد العالي ستقل بنسبة • 1\% ومن المتوقع أن ينأثز الخزان الجوفي في منطقة الدلتا سلبا الأمر الذي سيؤدى إلى انخفاض سطح المباه الجوفية في منطقة الدلتا. 
يتميز المشروع من وجهة نظر الصرف بأنه نظام مغلق حيث لا تتوافر مواقع طبيعية

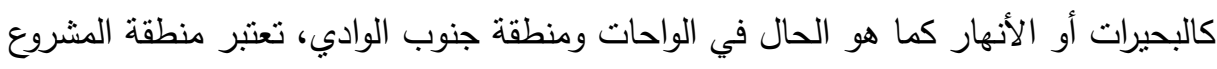

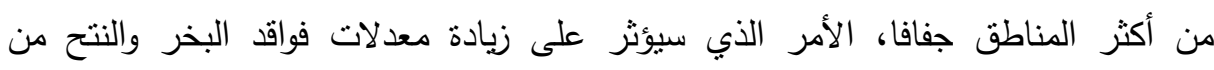
المساحات الخضراء ومن الأسطح المائية المكثوفة لذا وجب تحديد طرق الرئر الري وزراعة المحاصيل التي تتقق وبيئة المنطقة.

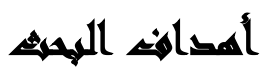

يتمثل هدف البحث الرئيسي في تقديم نموذج ( منهج ) مقترح لقياس التكلفة والعائد البيئي في المنشآت المائية ولتحقيق هذا الهدف يلزم تحقيق مجموعة من الأهداف الفرعية التالية: ا. توضيح منفعة نظام التكاليف في توفير المعلومات القادرة على ترشيد الأداء البيئي

$$
\text { للمشروعات المائية. }
$$

r. معرفة دور التكاليف البيئية في نقويم أداء المنشآت الصناعية المائية المقامة لخدمة

$$
\text { مشروع توشكي. }
$$

r. بناء نموذج مقترح يتلاءم والتطبيق على أداء المنشآت الصناعية المائية . ع. دراسة دور التكاليف البيئية في الحد من ظاهرة التلوث البيئي الناتج عن إقامة المشروعات

$$
\begin{aligned}
& \text { الصناعية المائية (لخدمة مشروع نوشكي) . } \\
& \text { ه. طرق قياس التكاليف والعوائد للمنشآت المائية }
\end{aligned}
$$

T. الاستفادة من النموذج المقدم من الدراسة في خدمة كل الهيئات والمنظمات المهتمة بقضايا البيئة بمصر ، من خلال إمكانية استخدامه وتطبيقه على المنشآت في القطاعات المماتلة، أو من خلال تطوير مراحل وخطوات دراسات الجدوى الاقتصادية للمشروعات باعتبار دراسة الجدوى البيئية للمشروع جزءا أساسيا منها ومكملا لها، بمعنى أنه يجب أبهات ألا يتم الموافقة والترخيص له إلا إذا ثبتت جدواه الاقتصادية المشنملة على التكاليف والمنافع 
V. تقديم إطار أو منهج مقترح لقياس التكاليف والمنافع البيئية لمنشآت القطاع المائى بما يخدم متخذي القرارات على كافة المستويات،

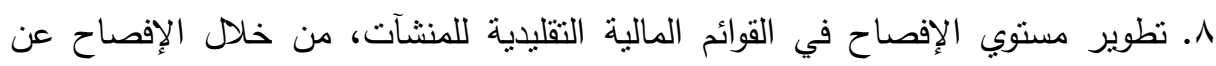
آثارها البيئية، متمثلا في الإفصاح عن التكاليف والعوائد البيئية الناجمة عن تلك المنشآته

\section{هروض اللجهي}

الفرض الأول: لا نوجد علاقة معنوية ذات دلالة إحصائية فيما بين نرشيد التكاليف في المنشآت المائية وبين ثقييم الأداء البيئي لهذه المنشآت. الفرض الثاني: لا توجد علاقة معنوية ذات دلالة إحصائية فيما بين ترشيد التكلفة والعائد في المنشآت المائية وكمية التلوث البيئي. الفرض الثالث: لا توجد علاقة معنوية ذات دلالة إحصائية فيما بين نتائج النموذج المقترح لقياس التكلفة والعائد في المنشآت المائية وبين ترشيد الأداء البيئي لمشروع دوله توشكي.

\section{هناهمج المهنش}

I المنهج التاريخي: لعرض الدراسات السابقة للتعرف على آراء ووجهات النظر للباحثين السابقين في هذا المجال.

Y. المنهج الوصفى: مجموعة الإجراءات البحثية التي تتكامل لوصف الظاهرة أو الموضوع اعتماداً على جمع الحقائق والبيانات وتصنيفها ومعالجتها وتحليلها تحليلاً كافياً ودقيقاً؛ لاستخلاص دلالتها والوصول إلى نتائج أو تعميمات عن الظاهرة أو الموضوع محل البحث مصادر جمع البيانات: 1- مصادر أولية: تتمثل في استمارة الاستقصاء والمقابلة الثخصية لتوزيع وجمع

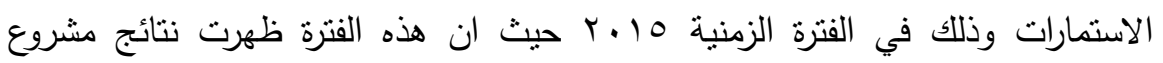


الدراسة بشكل كبير بعد مراجعة مشكلة الدراسة وفرضياتها قام الباحثون بتحديد محاور

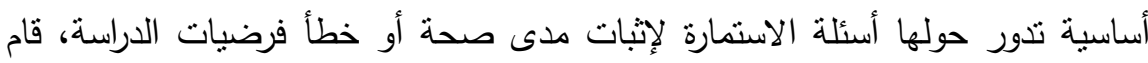

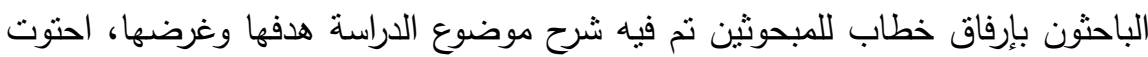
الاستمارة على قسمين رئيسيين. القسم الأول: تضمن البيانات الثخصية لأفراد عينة الدراسة، حيث يحتوي هذا الجزء على لئى بيانات حول العمر ، المؤهل العلمي، التخصص، المهنة، سنوات الخبرة ومدى علاقة أفراد،

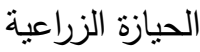
القسم الثاني: يحتوي على •r سؤال طلب من أفراد عينة الدراسة تحديد إجاباتهم عن كل

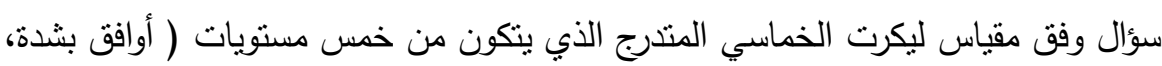

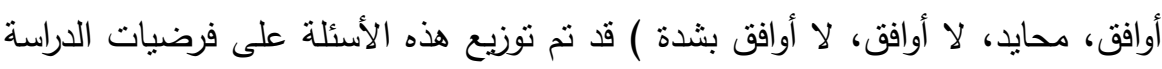

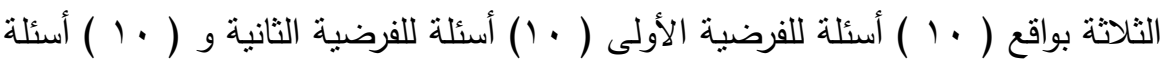
للفرضية الثالثة ., البيانات الأولية التي سيعتد عليها هذا البحث فقد تنثلت في البيانات الخاصة بالمتغيرات التي اشتملت عليها الدراسة ذات العلاقة بمشكلة وأهداف البحث وتمنلت مصادر الحصول على هذه البيانات فى مفردات عينات الدراسة التي سيتم جمعها. r- مصادر ثانوية تتمثل في الكتب والدوريات والمجلات والنشرات المتعلقة بموضوع الدراسة بالإضافة إلى رسائل الماجستير والدكتوراه والبحوث المنشورة وشبكة الإنترنت واشتملت

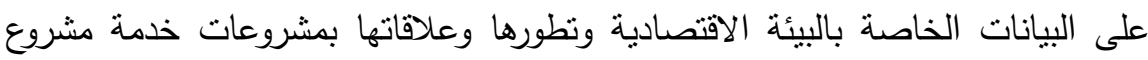
توشكى في مصر كما اشتملت هذه البيانات على الموضوعات الخاصة باتهات بالمنظمة

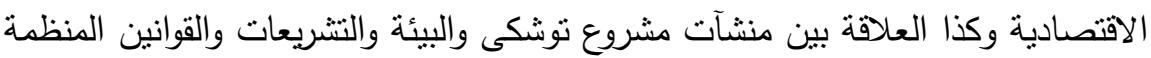
للبيئة فى مصر.

\section{Aats}

يقوم الباحثون بتتاول دراسة التكاليف البيئية وفق الحدود التالية:

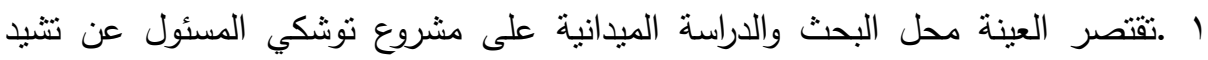
وإقامة مثل هذه المنشآت المائية وتحديدا (محطة الطلمبات الرئيسية، القناة الرئيسية

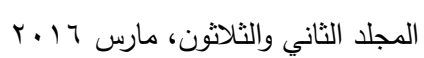


(المعروفة باسم قناة الثيخ زايد)، الفروع، مفيض والقنطرة و المسئول عن إقامة مثل هذه

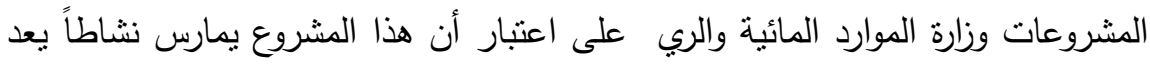

$$
\text { أحد المؤثرات البيئية. }
$$

r بيركز البحث على دراسة التكاليف البيئية و يقدم نموذج مقترح لقياس التكلفة والعائد في المنثآت المائية بهدف تقييم الأداء البيئي وطبيعة التكاليف البيئية ودورها في نقويم أداء

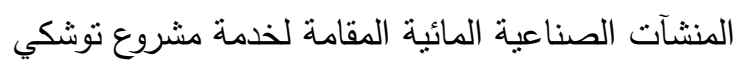

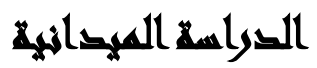

أسلوب معالجة وتحليل البيانات: لتحقيق أهداف البحث، فقد تم تحليل البيانات التي تم جمعها من خلال أداة الدراسة (الاستبانة) باستخدام الحاسب الآلي عن طريق برنامج الأساليب

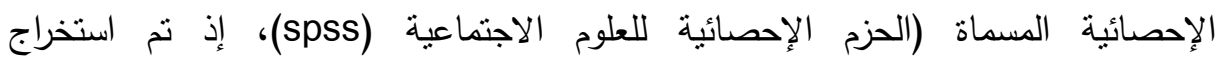
المتوسطات، والتوزيعات التكرارية والنسب المئوية. كما نم استخدام أسلوب التكرار والنسب الإنبة

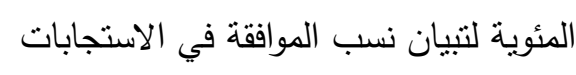

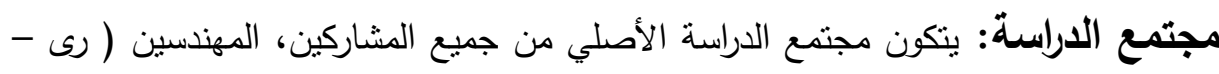

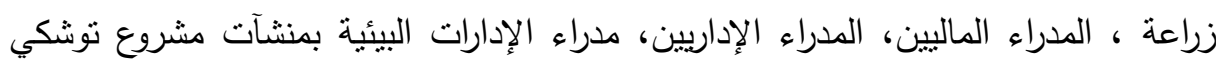

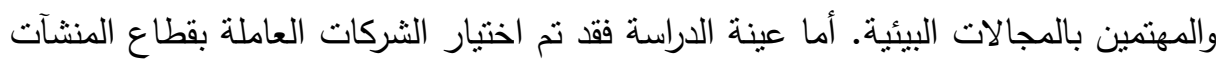

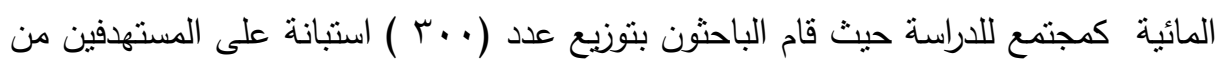

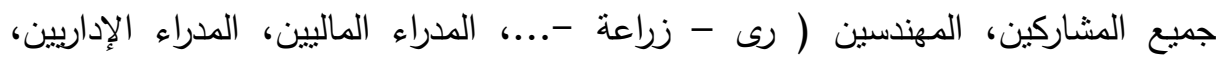

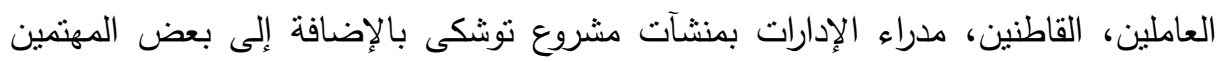
بالمجالات البيئية . صدق الاستبانة: يقصد بصدق أداة الدراسة الميدانية صدق تفسيرات نتائج الدراسة وإمكانية

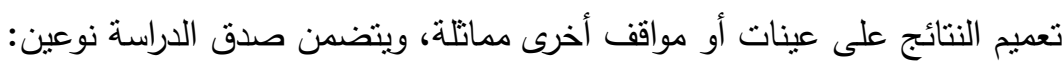


الصدق الداخلي Internal Validity : ويقصد به أن نتائج الدراسة تُعزى إلى المتغيرات موضوع القياس أو المعالجة المرتبطة بأهداف الدراسة. الصدق الخارجي External Validity : ويقصد به مدى إمكانية تعميم نتائج الدراسة على باهي عينات أو مواقف أخرى. ولقد اعتمد الباحثون من تحديد صدق الاستبانة على الصدق الظاهرى (صدق

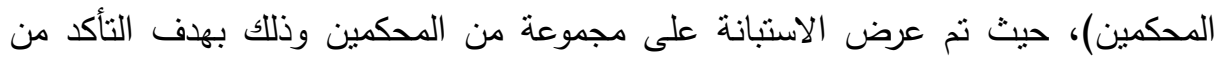
صدق الاستبانة، وتحديد مدى اتساق بنودها وعباراتها مع محاور البحث. ثبات الاستبانة وقد نم حساب معامل الثبات باستخدام معادلة " ألف كرونباخ" حيث إنها طريقة لحساب

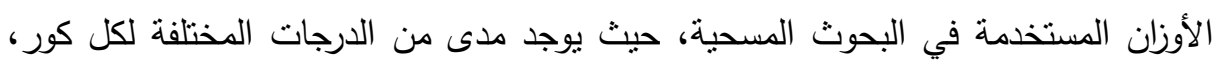
وذللك وفقاً للمعادلة الآتية(أبو علام رجاء محمود 991 ام)$$
\left(\frac{\dot{u}{ }^{r} \varepsilon r^{r}-1}{{ }^{r} \varepsilon}\right) \times \frac{\dot{u}}{(1-\dot{\varepsilon})}=\alpha
$$
حيث $\alpha$ = معامل الثبات. ع r ف = تباين الفترة الواحدة من الاستبانة. ع ع = = التباين الكلى للاستبانة.

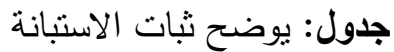

\begin{tabular}{|c|c|c|}
\hline الثبات & المحور & م \\
\hline$\cdot, \wedge \varepsilon$ & ترشيد التكاليف في المنشآت المائية و نتائج الأداء البيئي لهذه المنشآت. & 1 \\
\hline$\cdot, \wedge \mathrm{T}$ & ترشيد التكلفة والعائد في المنشآت المائية وكمية التلوث البيئى & $r$ \\
\hline$\cdot, \wedge \mathrm{V}$ & قياس التكلفة والعائد في المنشآت المائية وبين نرشيد الأداء البيئي & r \\
\hline$\cdot, \Lambda \mu$ & أهمية مثل هذه المشروعات. & $\varepsilon$ \\
\hline., 90 & الاستبيان ككل & 0 \\
\hline
\end{tabular}

ومن خلال النتائج السابقة يتضح أن معدلات ثنات كل محور عالية باستثناء

المحور الربع (rی, •) وهو يعد مقبولاً إلى حد ما، ويعوضه نسبة الثبات للاستبانة ككل 


\section{الختمار المزوضه}

اختبار الفرضية الاولى: لا توجد علاقة معنوية ذات دلالة إحصائية فيما بين ترشيد التكاليف في المنشآت المائية وبين نتائج الأداء البيئي لهذه المنثآت.

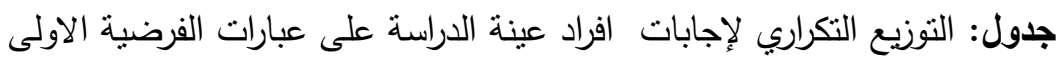

\begin{tabular}{|c|c|c|c|c|c|}
\hline لا لا أوافق & أو الوافقي & محايد & 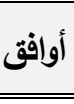 & 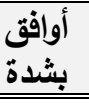 & 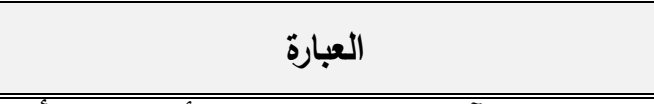 \\
\hline & $r$ & $\Lambda$ & $r$. & r. & تلأدتبرت النطنشآت خدماتهائة تقييم الأداء من أهم \\
\hline & $\varepsilon$ & $r r$ & $T \varepsilon$ & $\Lambda$ & تحديداًٌ هذه الأهية لها تأثير على ترشيد التكاليف \\
\hline & & $r$. & rT & $1 \varepsilon$ & تقييم أدائها المنشآت بالتكاليف البيئيه بساعدها في \\
\hline & 7 & rT & 11 & $\varepsilon$ & إلى تطوير الأداء وتحسينة عن التكاليف البيئية سوف يؤدي \\
\hline & $\varepsilon$ & rA & Kr & $\varepsilon$ & صلي ثقوية قياس الداء التكاليفة البيئية للمنشأة يؤثز سلبا \\
\hline & & $\varepsilon$ & $r \varepsilon$ & rT & 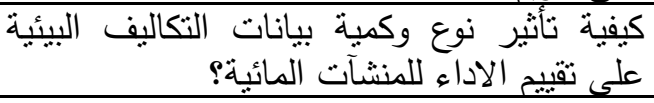 \\
\hline & & ir & $T \varepsilon$ & $T \varepsilon$ & 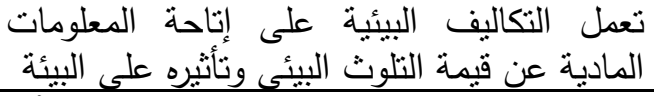 \\
\hline & $r$ & Kr & $1 \leq$ & r & 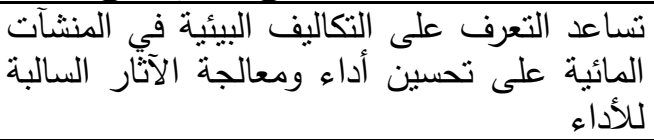 \\
\hline & & $r$ & 1. & rᄉ & 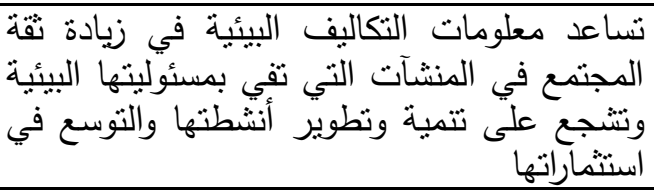 \\
\hline- & - & - & - & - & المعلومات عن التكاليف البيئية متوفرة \\
\hline
\end{tabular}

المصدر: إعداد الباحثون بالاعتماد على بيانات الاستبانة 10 ـ ب م الم 
للتحقق من صحة هذه الفرضية، ينبغي معرفة اتجاه آراء عينة الدراسة بخصوص كل سؤال من الأسئلة المتعلقة بالفرضية الاولى، ثم يتم حساب الوسيط لإجابات أفراد عينة الدراسة على كل سؤال وعلى الأسئلة مجنمعة.

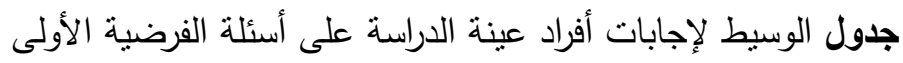

\begin{tabular}{|c|c|c|}
\hline التفسير & الوسيط & 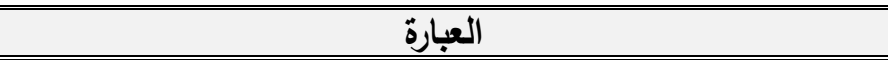 \\
\hline 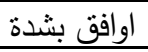 & 1. & تعتبر المنشآت المائية تقييم الأداء من أهم الأدوات لنظوير خدماتها \\
\hline اوافق & $\Lambda$ & هل هذه الأهمية لها تأثثر على ترشيد التكاليف تحديداً؟ \\
\hline 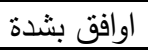 & 1. & اهتمام المنشآت بالتكاليف البيئية يساعدها فى تقييم أدائها؟ \\
\hline محايد & 7 & وتحبين المحاسبة عن التكاليف البيئية سوف يؤدي إلى تطوير الأداء \\
\hline محايد & 7 & المنشأةبة قياس التكاليف البيئية للمنشأة يؤثز سلبا على تقييم أداء \\
\hline اوافق بشدة & 1. & المأثثير نوع وكمية بيانات التكاليف البيئية على تقييم الاداء للمنشآت \\
\hline 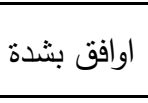 & 1. & تالبيئى والتثاليف على البيئية على إتاحة المعلومات المادية عن قيمة التلوث \\
\hline 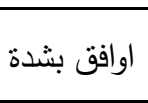 & 1 . & 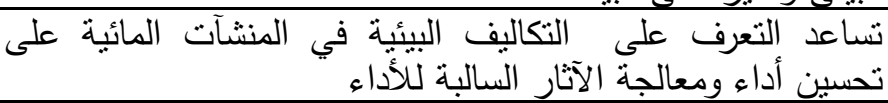 \\
\hline 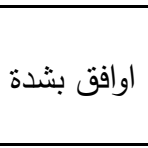 & 1. & 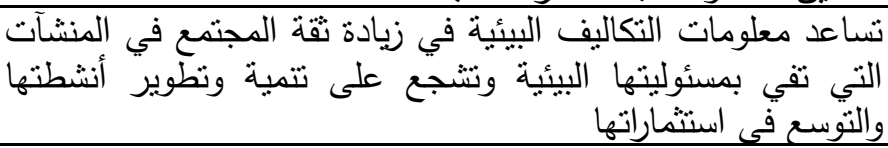 \\
\hline لا بشدة اوفق & • & المعلومات عن التكاليف البيئية متوفرة \\
\hline
\end{tabular}

المصدر: إعداد الباحثّن بالاعتماد على بيانات الاستبانة 10 ـr م من خلال الجدول يتضح ما يلي:

ا. بلغت قيمة الوسيط لإجابات أفراد عبنة الدراسة على العبارة الأولى ( • ( ) يعني ذلك أن

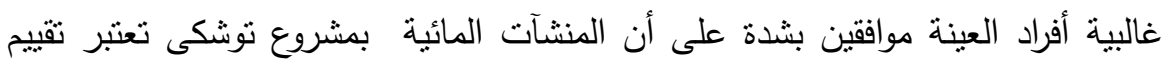
الأداء من أهم الأدوات لتطوير خدماتها.

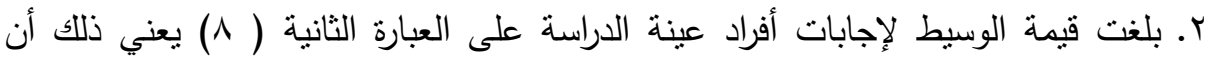

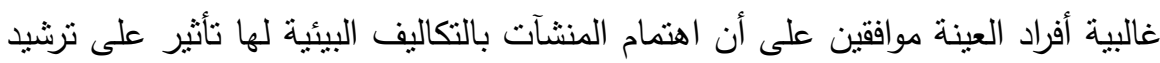
التكاليف تحديداً.

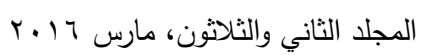


r. بلغت قيمة الوسيط لإجابات أفراد عينة الدراسة على العبارة الثالثة ( • () يعني ذلك أن

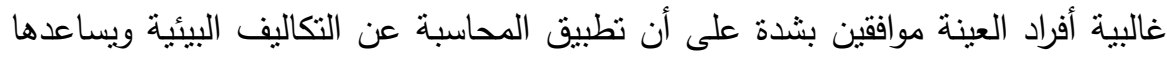

$$
\text { في تقيبم أدائها. }
$$

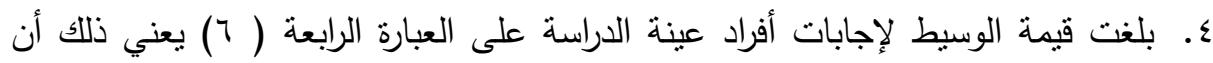

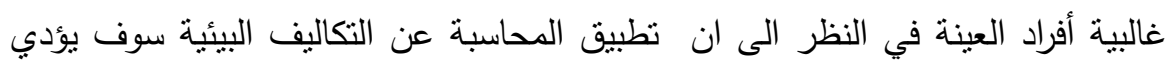

$$
\text { إلى تطوير الأداء وتحسينه. }
$$

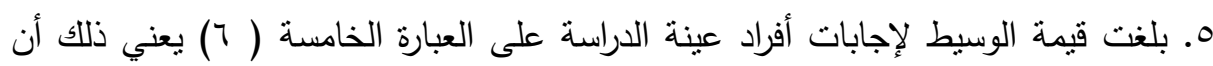
غالبية أفراد العينة محايدين في النظر على أن صعوبة قياس التكاليف البيئية للمنشأة يؤثر

$$
\text { سلبا على تقييم أداء المنشأة. }
$$

7. بلغت قيمة الوسيط لإجابات أفراد عينة الدراسة على العبارة السادة ( • • (1) يعني ذلك أن غالبية أفراد العينة موافقين بشدة على أن تأثثر نوع وكمية بيانات التكاليف البيئية على الئه تقييم الاداء للمنشآت المائية

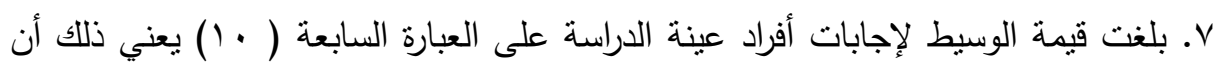

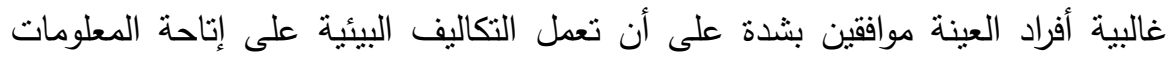
المادية عن قيمة التلوث البيئي وتأثثره علي البيئة.

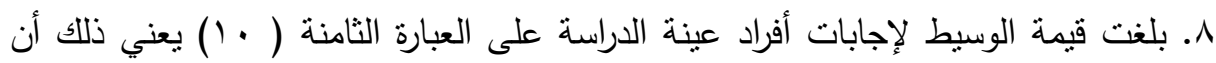

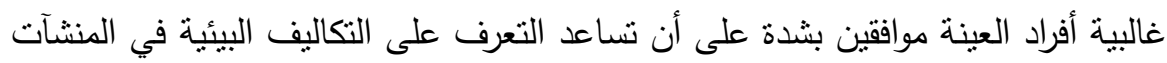
المائية على تحسين أداء ومعالجة الآثار السالبة للأداء.

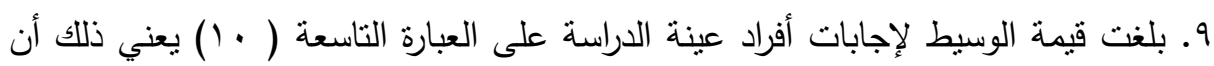
غالبية أفراد العينة موافقين بشدة على أن تناعد معلومات التكاليف البيئية في زيادة ثقة المجتمع في المنشآت التي تفي بمسئوليتها البيئية وتشجع على تنمية ونسية وتطوير أنشطتها

$$
\text { والتوسع في استثماراتها. }
$$

• 1. بلغت قيمة الوسيط لإجابات أفراد عينة الدراسة على جميع عبارات الفرضية الأولي (^,^) 
الأولى وبعض الأفراد لا يدرون أو غير موافقين على ذلك مما تقدم تخلص الباحثون إلى تحقق فرضية الدراسة الأولى لكل عبارة من العبارات المتعلقة بها، وللتحقق من صِحة الاحته

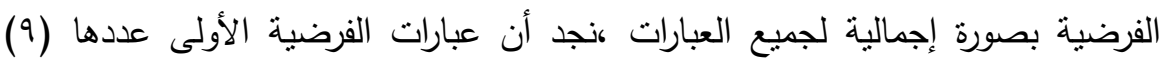

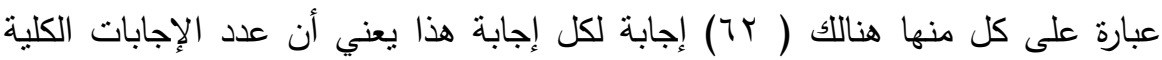

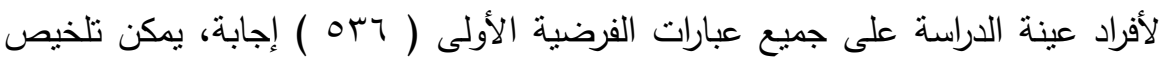

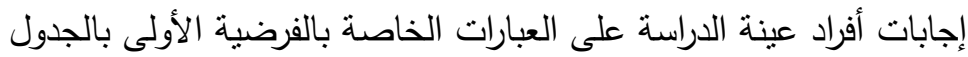

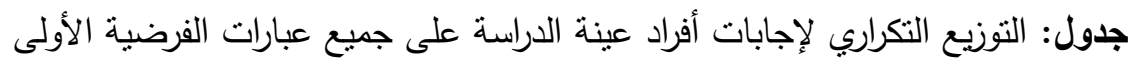

\begin{tabular}{|c|c|c|}
\hline النسبة المئوية & العدد ال العد & الاجابة \\
\hline$\% r r, \wedge$ & $1 V 7$ & اوافق بشدة \\
\hline$\%$ \% , , & 194 & اوافق \\
\hline$\% \curlyvee \wedge$ & 10. & محايد \\
\hline$\% \Upsilon, \varepsilon$ & 11 & لا اوافق \\
\hline$\cdot$ & . & لا اوافق بشدة \\
\hline$\% 1 \ldots$ & Ort & المجموع \\
\hline
\end{tabular}

المصدر: إعداد الباحثون بالاعتماد على بيانات الاستبانة 10 • ب م الم

تلاحظ أن عينة الدراسة تضمنت بنسبة (

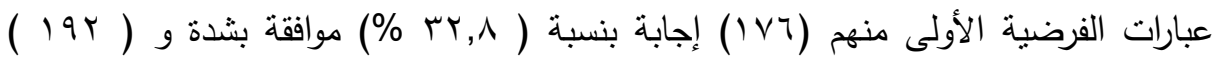

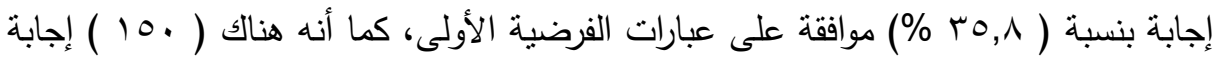

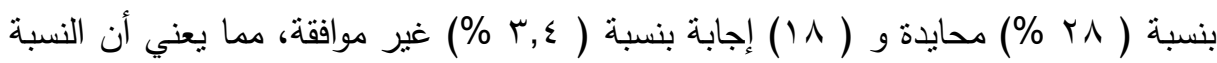
الغالبة من أفراد الدراسة موافقة على الفرضية الأولى التي تتص على على أن " لا توجد علاقة معنوية ذات دلالة إحصائية فيما بين ترشيد التكاليف في المنشآت المائية وبين نتائج الأداء

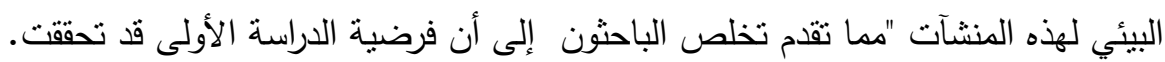


اختبار الفرضية الثانية: لا توجد علاقة معنوية ذات دلالة إحصائية فيما بين ترشيد التكلفة والعائد في المنشآت المائية وكمبة التلوث البيئي. جدول: التوزيع التكراري لإجابات افراد عينة الدراسة على عبارات الفرضية الثانية

\begin{tabular}{|c|c|c|c|c|c|}
\hline 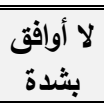 & اوافق لا & محايد & أوافق & 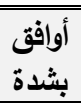 & العبارة \\
\hline & 7 & 7 & YT & $r$. & بيئي فيها؟ أهمية للمنشآت المائية لوجود نظام محاسبة \\
\hline & & $\varepsilon$ & rr & $r \varepsilon$ & 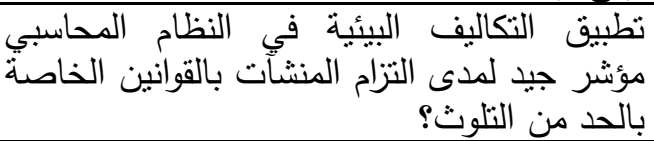 \\
\hline & & $\wedge$ & r. & Yr & 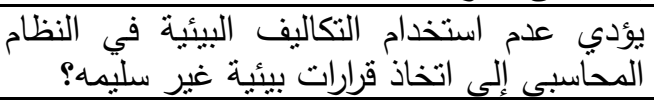 \\
\hline & & $\varepsilon$ & rᄉ & 11 & القرارات الإدارية التكاليفة بالبيئية الإدارة في اتخاذ \\
\hline & & $\Lambda$ & $\varepsilon$. & IT & 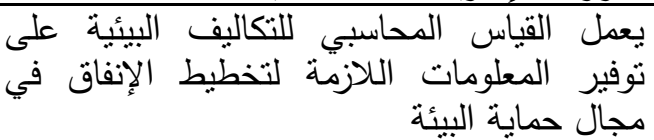 \\
\hline & $\Lambda$ & $r$ & r. & 1. & 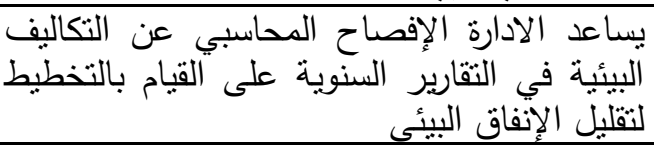 \\
\hline & & $\Lambda$ & Tr & r. & 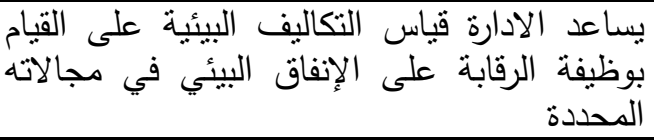 \\
\hline & 7 & $1 \leq$ & $T \varepsilon$ & 17 & 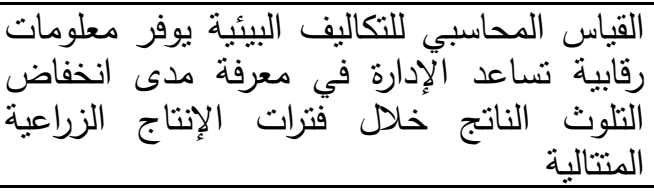 \\
\hline & $r$ & $1 \varepsilon$ & Ir & 7 & لتخؤديط قياس الإنفاق فيكاليف مجال حمائية لإحكام البيئة الرقابة اللازمة \\
\hline & 1. & YY & ir & 17 & 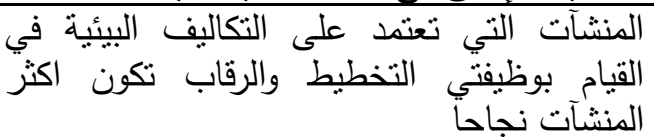 \\
\hline
\end{tabular}

المصدر: إعداد الباحثون بالاعتماد على بيانات الاستبانة 10 ـ ب م 
جدول: الوسيط لإجابات أفراد عينة الدراسة على أسئلة الفرضية الثانية

\begin{tabular}{|c|c|c|}
\hline التفسير & الوسيط & 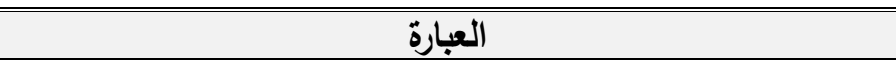 \\
\hline أوافق & $\wedge$ & هناك اهمية للمنشآت المائية لوجود نظام محاسبة بيئي فيها؟ \\
\hline 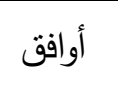 & 1. & 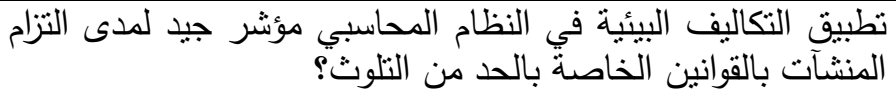 \\
\hline 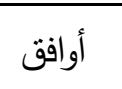 & $\Lambda$ & قرواردات علئمة استخدام التكاليف البيئية في النظام المحاسبي إلى اتخاذ \\
\hline 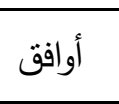 & $\wedge$ & المتعلقة قالبيئة التكاليف البيئية الإدارة في اتخاذ القرارات الإدارية \\
\hline أوافق & $\Lambda$ & 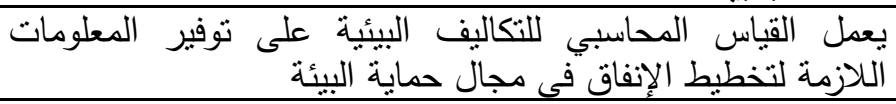 \\
\hline محايد & 7 & 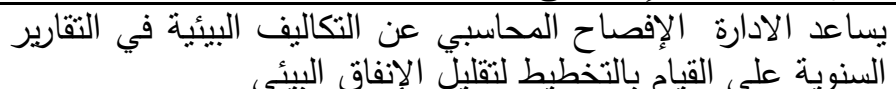 \\
\hline 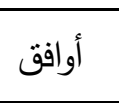 & $\wedge$ & الإنفاقد البيئي في قيار الاتها ألمحددة البيئية على القيام بوظيفة الرقابة على \\
\hline 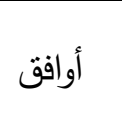 & $\wedge$ & 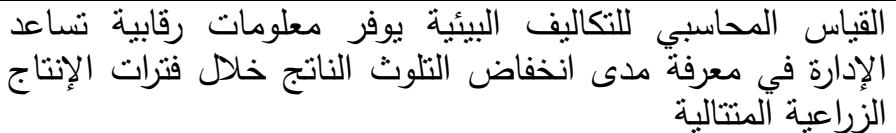 \\
\hline محايد & 7 & فؤدى قياس حماية البيئة البيئية لإحكام الرقابة اللازمة لتخطبط الإنفاق \\
\hline محايد & 7 & 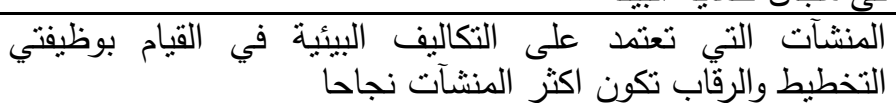 \\
\hline
\end{tabular}

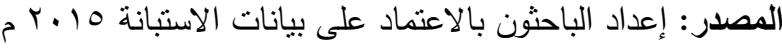
من خلال الجدول بيضتح ما يلي:

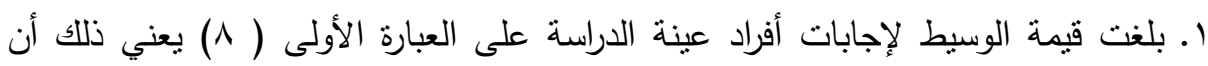

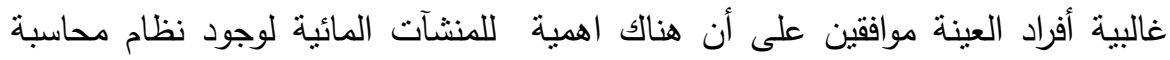

$$
\text { بيئي فيها. }
$$

r. بلغت قيمة الوسيط لإجابات أفراد عينة الدراسة على العبارة الثانية ( • (1) يعني ذلك أن

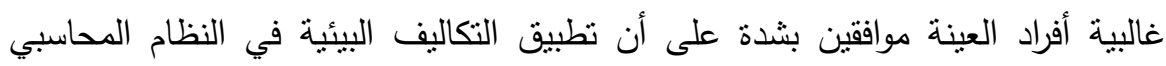
مؤشر جيد لمدى التزام المنشآت بالقوانين الخاصة بالحد من التلوث.

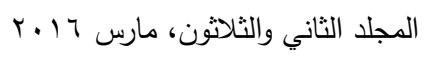


r. بلغت قيمة الوسيط لإجابات أفراد عينة الدراسة على العبارة الثالثة ( ^) يعني ذللك أن غالبية أفراد العينة موافقين على أن يؤدي عدم استخدام التكاليف البيئية في النظام المحاسبي إلى اتخاذ قرارات بيئية غير سليمه.

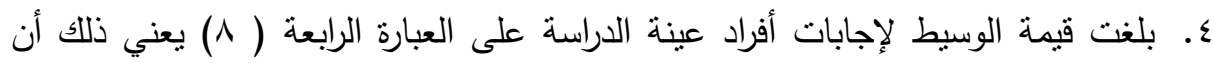

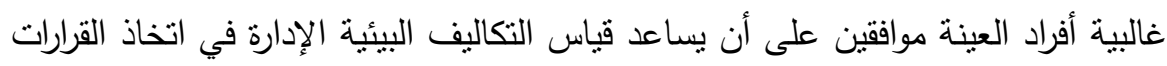
الإدارية المتعلقة بالبيئة.

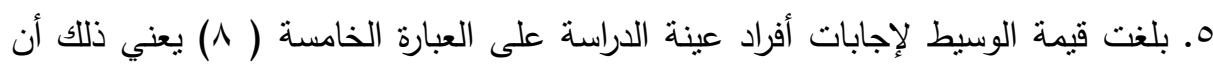

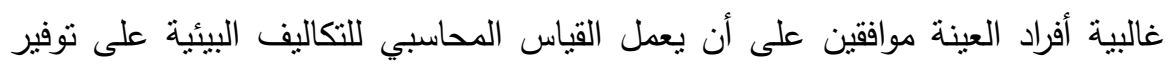
المعلومات اللازمة لتخطيط الإنفاق في مجال حماية البيئة.

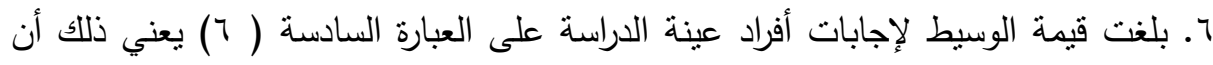

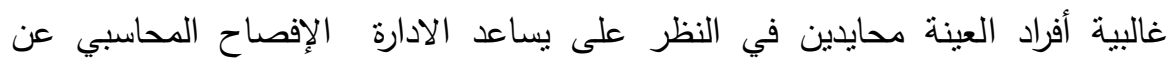
التكاليف البيئية في التقارير السنوية على القيام بالتخطبط لتقليل الإنفاق البيئي.

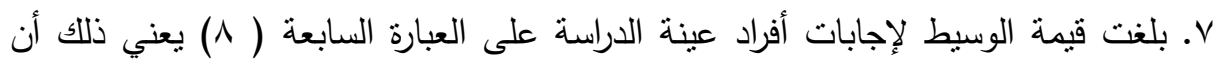
غالبية أفراد العينة موافقين على أن يساعد الادارة قياس التكاليف البيئية على القيام بوظيفة الرقابة على الإنفاق البيئي في مجالاته المحددة.

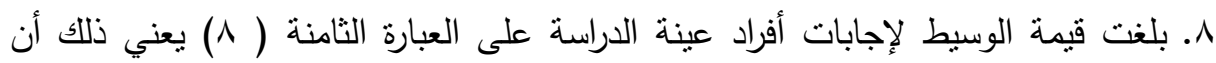
غالبية أفراد العينة موافقين على أن القياس المحاسبي للتكاليف البيئية يوفر معلومات رقابية الباتية تساعد الإدارة في معرفة ددى انخفاض التلوث الناتج خلال فترات الإنتاج الزراعية المنتالية 9. بلغت قيمة الوسيط لإجابات أفراد عينة الدراسة على العبارة التاسعة ( 7) يعني ذلك أن غالبية أفراد العينة محايدين فى النظر على أن يؤدى قياس التكاليف البيئية لإحكام الرقابة لإبة لإنهات اللازمة لتخطبط الإنفاق في مجال حماية البيئة. 
• 1 ـ بلغت قيمة الوسيط لإجابات أفراد عينة الدراسة على العبارة التاسعة ( آ) يعني ذلك أن غالبية أفراد العينة محايدين فى النظر على أن المنشآت التي تعتمد على التكاليف البيئية في القيام بوظيفتي التخطيط والرقاب تكون اكثر المنشآت نجاحا. 11. بلغت قيمة الوسيط لإجابات أفراد عينة الدراسة على جميع عبارات الفرضية الثانية (؟,^)

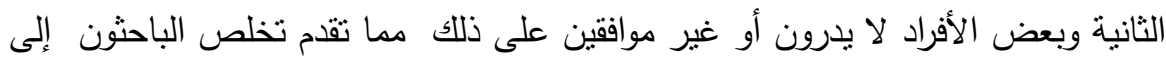
تحقق فرضية الدراسة الثانية لكل عبارة من العبارات المتعلقة بها، وللتحقق من صِحة

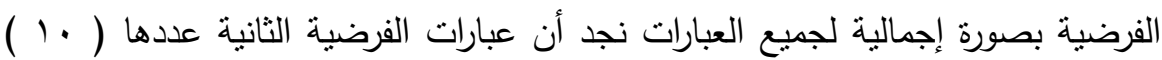
عبارة هنالك ( T T ) إجابة على كل منها هذا يعني أن عدد الإجابات الكلية لأفراد عينة

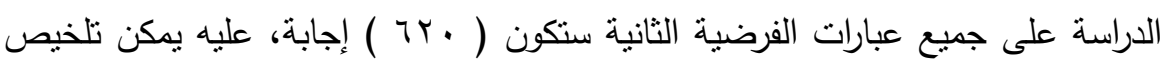
إجابات أفراد عينة الدراسة على العبارات الخاصة بالفرضية الثانية بالجدول التالي. جدول: التوزيع التكراري لإجابات أفراد عينة الدراسة على جميع عبارات الفرضية الثانية

\begin{tabular}{|c|c|c|}
\hline النسبة المئوية & العدد & الاجابة \\
\hline$\%$ \% q, & $1 \wedge \varepsilon$ & اوافق بشدة \\
\hline$\% \leqslant \varepsilon, \wedge$ & rVA & اوافق \\
\hline$\% r$. & IYE & محايد \\
\hline$\% 0, \varepsilon$ & Tะ & لا اوافق \\
\hline . & - & لا اوافق بشدة \\
\hline$\% 1 \ldots$ & $\pi r$. & المجموع \\
\hline
\end{tabular}

تلاحظ الباحثون أن عينة الدراسة تضمنت من خلال الجدول السابق

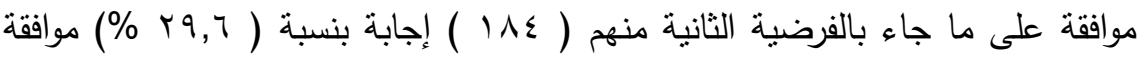

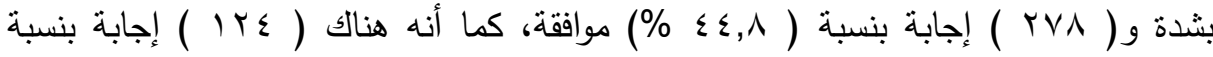

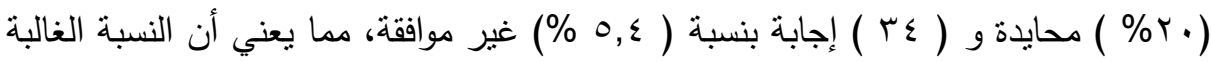

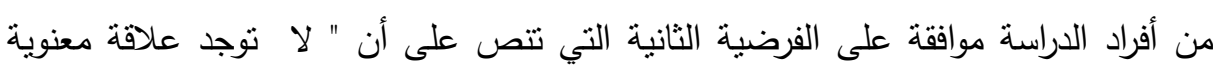
ذات دلالة إحصائية فيما بين ترشيد التكلفة والعائد في المنشآت المائية وكمية التلوث البيائي. " مما تقدم تخلص الباحثُون إلى أن فرضية الدراسة الثانية قد تحققت

$$
\text { المجلد الثاني والثلاثون، مارس } 17 \text { ـ }
$$


اختبار الفرضية الثالثة: لا نوجد علاقة معنوية ذات دلالة إحصائية فيما بين نتائج النموذج

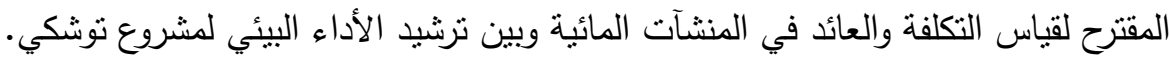
جدول: التوزيع التكراري لإجابات افراد عينة الدراسة على عبارات الفرضية الثالثة

\begin{tabular}{|c|c|c|c|c|c|}
\hline بثشدة أوافق & 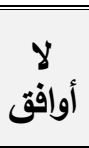 & محايد & أوافق & 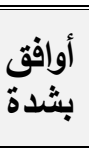 & العبارة \\
\hline$r$ & 17 & $r$. & $r$. & 1 & لاصى كل بها بخصوص المنشآت التكاليفية البيئية محاسبيه \\
\hline \multirow[t]{9}{*}{$r$} & Ir & YT & r. & & 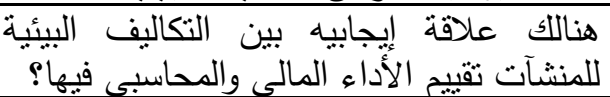 \\
\hline & $\varepsilon$ & r. & $1 \varepsilon$ & ir & 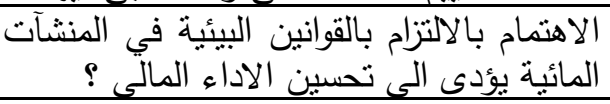 \\
\hline & $\varepsilon$ & $1 \varepsilon$ & Tr & 1. & تقييم أدائها قياس التكاليف البيئية للمنشآت في \\
\hline & $r$ & Ir & r & 1. & 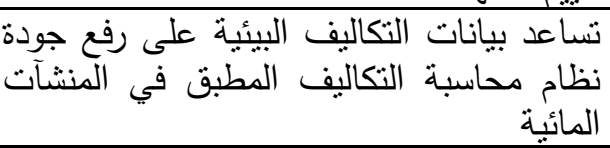 \\
\hline & $r$ & $\wedge$ & $\varepsilon r$ & $\wedge$ & 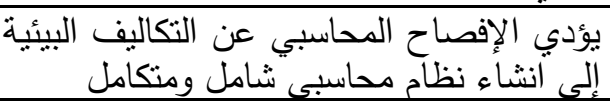 \\
\hline & & 11 & Tr & 1. & تطعلير القياس الأداء المالي وألمحاسبي للتكاليف في البيئية المنشآتى \\
\hline & $r$ & 7 & 11 & $r \varepsilon$ & 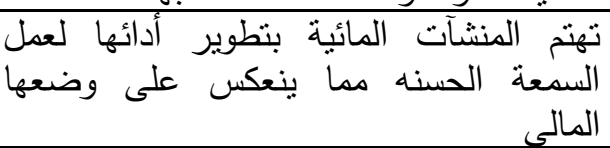 \\
\hline & & rr & $T \varepsilon$ & $1 \varepsilon$ & 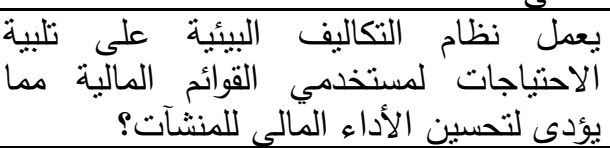 \\
\hline & & $1 \varepsilon$ & $r \varepsilon$ & Ir & 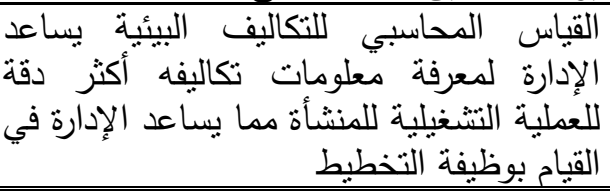 \\
\hline
\end{tabular}

المصدر: إعداد الباحثون بالاعتماد على بيانات الاسنبانة 0 ــ م 
للتحقق من صحة هذه الفرضية، ينبغي معرفة إتجاه آراء عينة الدراسة بخصوص كل سؤال من الأسئلة المتعلقة بالفرضية الثالثة، ثم يتم حساب الوسيط لإجابات أفراد عينة الدراسة على كل سؤال والأسئلة مجتمعة الناه

جدول: الوسيط لإجابات أفراد عينة الدراسة على أسئلة الفرضية الثالثة

\begin{tabular}{|c|c|c|}
\hline التفسير & الوسيط & العبارة \\
\hline أوافق & $\Lambda$ & لالتكاليف كل البيئية المنشآت المائية سياسه محاسبيه خاصه بها بخصوص \\
\hline محايد & 7 & هناللك علاقة إيجابيه بين التكاليف البيئية للمنشآت نقييم الأداء \\
\hline محايد & 7 & تحسين الاداء الماللي بالقوانين البيئية في المنشآت المائية يؤدى الى \\
\hline أوافق & $\Lambda$ & بساعد قياس التكاليف البيئية للمنشآت في تقييم أدائها \\
\hline أوافق & $\Lambda$ & تساعد بيانات المنشآت المائية البيئية على رفع جودة نظام محاسبة التكاليف \\
\hline أوافق & $\Lambda$ & يؤدبي الإفصامل ومتكامل المحبي عن التكاليف البيئية إلى انثاء نظام \\
\hline أوافق & $\Lambda$ & 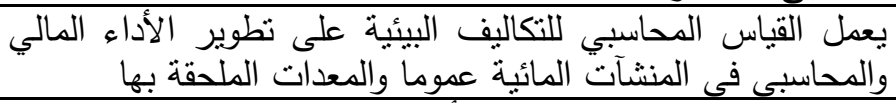 \\
\hline أوافق بشدة & 1. & تينعكس المنشآت المائية بتطوير أدائها لعمل السمعة الحسنه مما \\
\hline أوافق & $\Lambda$ & المالية مما يؤدى التكاليف التحسيئية الأداء المالّي للمنشآتية الاحات لمستخدمي القوائم \\
\hline أوافق & $\Lambda$ & 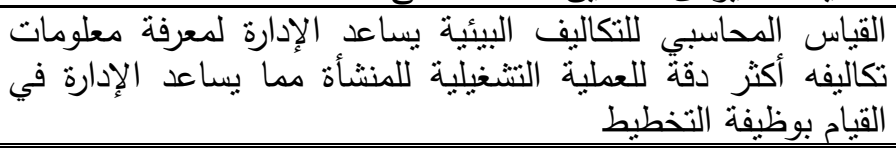 \\
\hline
\end{tabular}

المصدر: إعداد الباحثنون بالاعتماد على بيانات الاسنبانة 10 ب م م من خلال الجدول يتضح ما يلي:

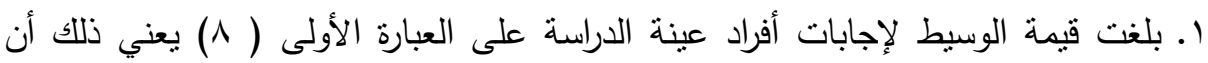
غالبية أفراد العينة موافقين على أن لدى كل من لإى كل من المنشآت المائية سياسه محاسبيه خاصه بها بخصوص التكاليف البيئية. 
r. بلغت قيمة الوسيط لإجابات أفراد عينة الدراسة على العبارة الثانية ( T) يعني ذلك أن غالبية أفراد العينة محايدين في النظر إلى أن هناللك علاقة إيجابيه بين التكاليف البيئية

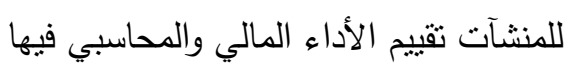

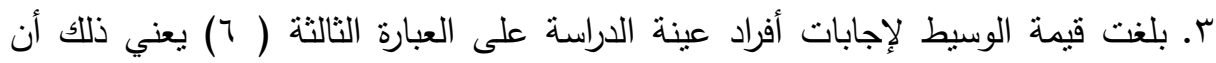
غالبية أفراد العينة محايدين في النظر على أن الاهتمام بالالتزام بالقوانين البيئية في

$$
\text { المنشآت المائية يؤدى الى تحسين الاداء المالي. }
$$

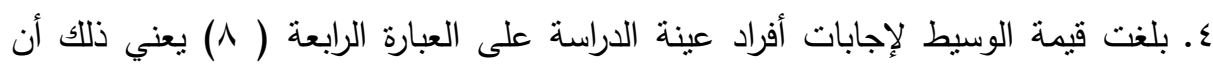
غالبية أفراد العينة موافقين على أن يساعد قياس التكاليف البيئية للمنشآت في تقييم أدائها.

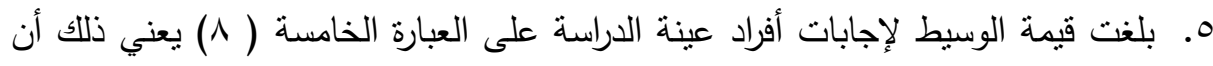
غالبية أفراد العينة موافقين على أن تساعد بيانات التكاليف البيئية على رفع جودة نظام محاسبة التكاليف المطبق في المنشآت المائية

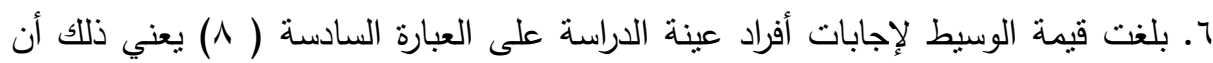

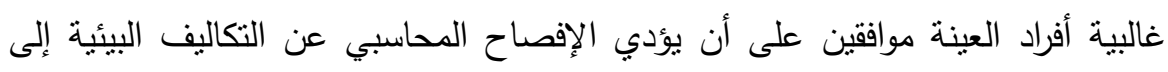
انشاء نظام محاسبي شامل ومتكامل

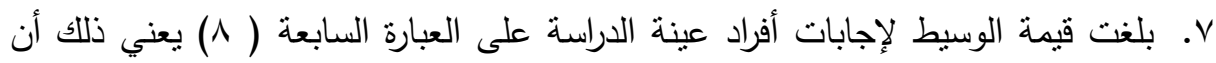

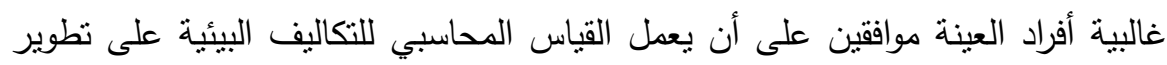

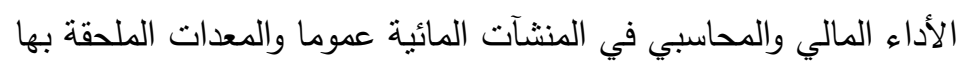

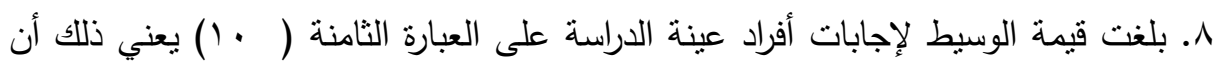

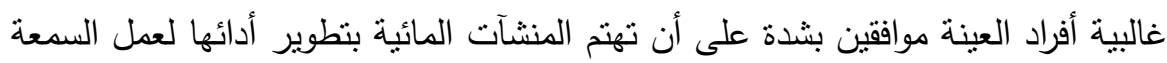

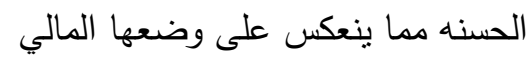
9. بلغت قيمة الوسيط لإجابات أفراد عينة الدراسة على العبارة التاسعة ( ^ ع) يعني ذللك أن

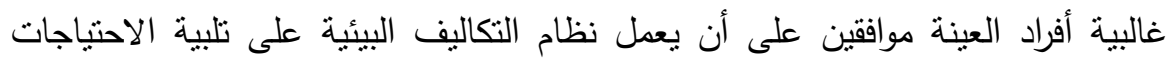
لمستخدمي القوائم المالية مما يؤدى لتحسين الأداء المالي للمنشآت. 


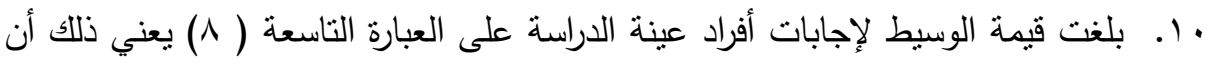
غالبية أفراد العينة موافقين على أن القياس المحاسبي للتكاليف البيئية يساعد الإدارة لمعرفة لإنة

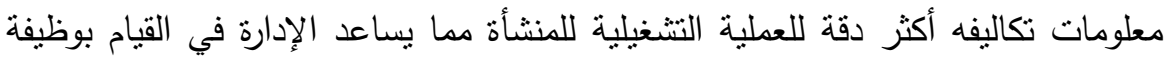

التخطيط.

بلغت قيمة الوسيط لإجابات أفراد عينة الدراسة على جميع عبارات الفرضية الثالثة ( 1 ( ) مما يعني أن معظم أفراد عينة الدراسة موافقين على ما جاء بعبارات الفرضية الثالثة

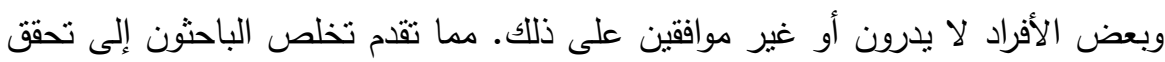
فرضية الدراسة الثالثة لكل عبارة من العبارات المتعلقة بها، وللتحقق من صِحة الفرضية

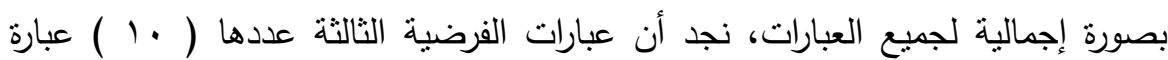

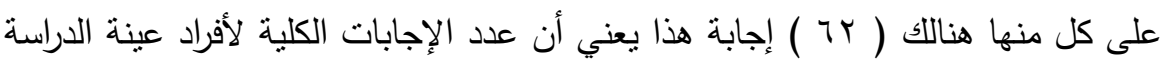

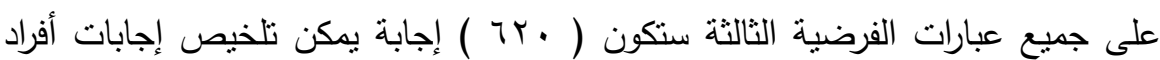

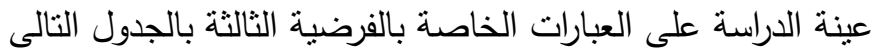
جدول: التوزيع التكراري لإجابات أفراد عينة الدراسة على جميع عبارات الفرضية الثالثة

\begin{tabular}{|c|c|c|}
\hline النسبة المئوية & العدد & الاجابة \\
\hline$\% \backslash \wedge, 7$ & $11 \%$ & اوافق بشدة \\
\hline$\% \leqslant 0, r$ & TVY & اوافق \\
\hline$\% \curlyvee \wedge, r$ & IV. & محايد \\
\hline$\% V$ & $\varepsilon r$ & لا اوافق \\
\hline$\% 1, \varepsilon$ & $\varepsilon$ & لا اوافق بشدة \\
\hline$\% 1 \ldots$ & $T r$. & المجموع \\
\hline
\end{tabular}

المصدر: إعداد الباحثن بالاعتماد على بيانات الاستبانة 10 • Y م

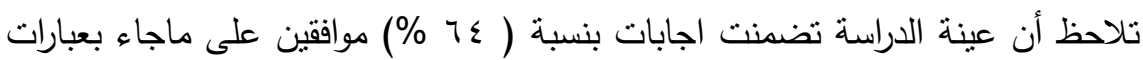

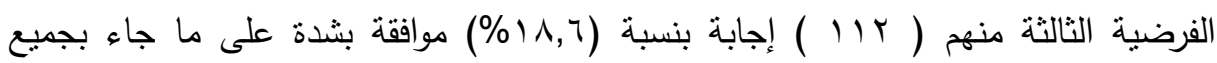

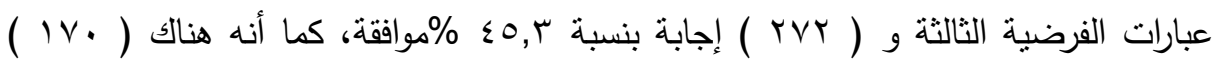

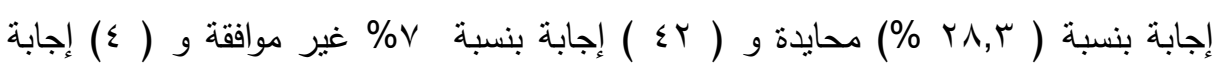

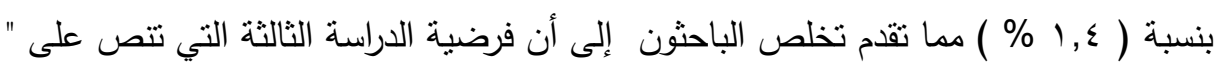

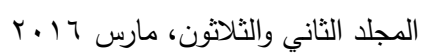


لا توجد علاقة معنوية ذات دلالة إحصائية فيما بين نتائج النموذج المقترح لقياس التكلفة

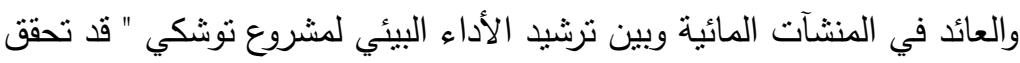

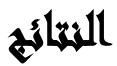

• توصلت الدراسة الى انه لا يوجد علاقة ذات دلالة إحصائية ما بين التكاليف والإفصاح

البيئي في ترشيد القرارات الإدارية بمنطقة الدراسة.

• توصلت الدراسة الى انه لا يوجد علاقة ذات دلالة إحصائية ما بين التكاليف والإفصاح

البيئي ومدى تطبيقها بيئيا بمنطقة الدراسة.

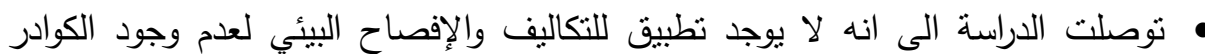

البشرية المؤهلة بمنطقة الدراسة

• توصلت الدراسة الى أن الدوافع والأمور التي تقوم بها الادارة المسئولة لاهتمام بالقضايا

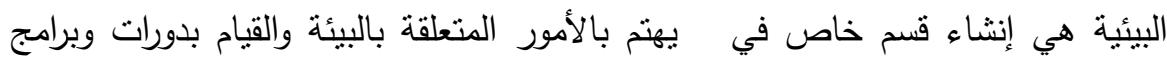

توعية متتالية لموظفي الادارة لنشر الوعي البيئي وتحسين الصورة أمام الجهات المختلفة

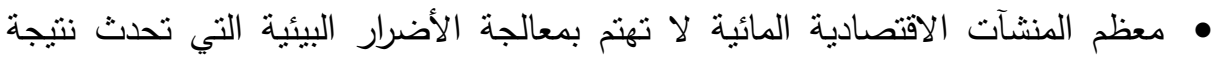

عملياتها التشغيلية.

• إدراج التكاليف البيئية في النظام المحاسبي يعطي صورة صحيحة عن تكاليف المنشأة مما

يساعد في تقويم أدائها . 
طارق عبد العال وآخرون

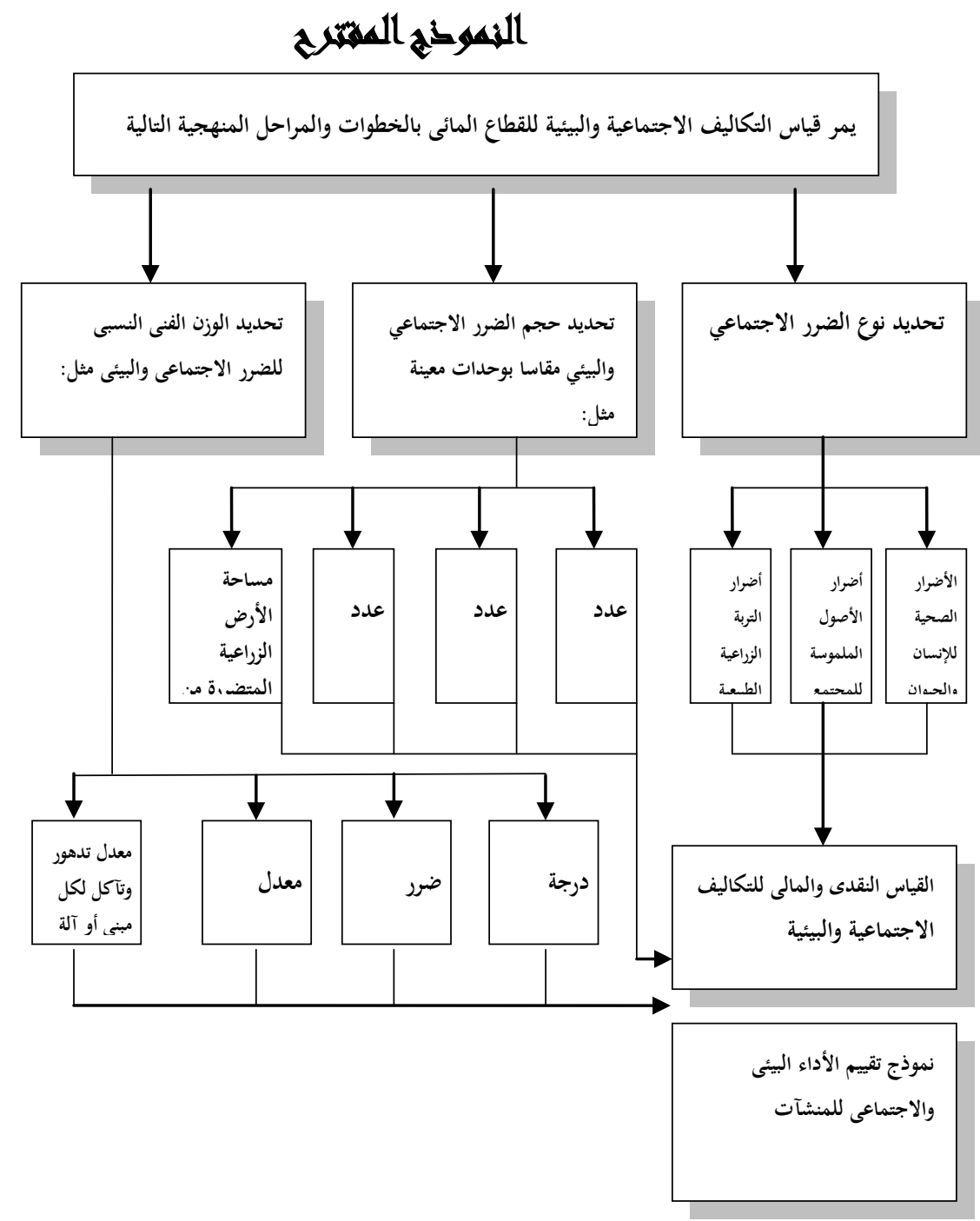

المجلد الثاني والثالثون، مارس 7 ب ا 


\section{اللزوسياتي}

1. أهمية الاهتمام بالتكاليف البيئية وإدراجها ضمن التكاليف التشغيلية للمنشأة . r. تطبيق المنهج المقترح لقياس التكلفة والعائد البيئي في المنشآت المائية

قدمت الدراسة الحالية نموذجًا لقياس نكاليف التلوث البيئى للقطاع المائى منمثلا في

إحدى قطاعاته الفرعية وهو قطاع المنشآت المائية وهو يتضمن الخطوات المنهجية التالية : (أ) تحديد نوع الضرر المتوقع من التلوث؛ (ب) تحديد حجم الضرر أو القياس الكمى للضرر؛

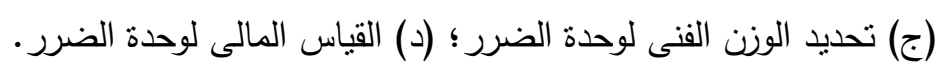
هذا ويعتبر قياس تكاليف أضرار ومعالجة التلوث في اقامة المنشآت المائية، من خلال تطبيق النموذج السابق، أمرا ضروريا لأغراض توفير البيانات والمعلومات اللازمة لتحليل تكلفة

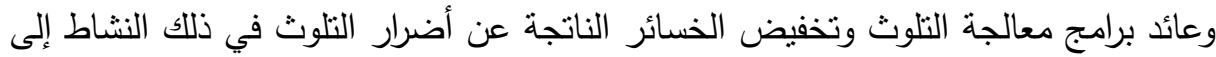
أدنى حد ممكن وأيضا لإجراء الدراسات الاقتصادية والمالية

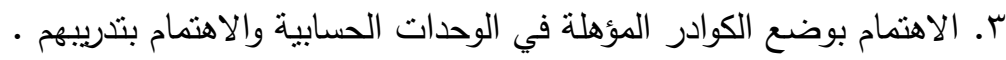

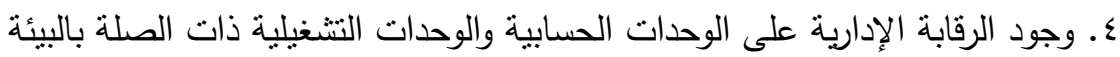
ه. تفعيل القوانين التي تلزم المنشآت بتحمل مسؤولياتها تجاه البيئة.

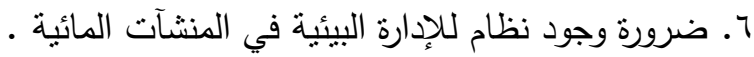
V. الاهتمام بزيادة الوعي البيئي لدى مستخدمي القوائم المالية و العامة والعمل على الئه فئن المحافظة ^. ضرورة اقتتاء المنشآت لأصول ذات تقنية منطورة لرصد أو منع أسباب التلوث الناتج عن

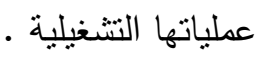
9 ـ الاهتمام بالتقييم كأداة لتحسين أداء المنشآت وذلك بشكل دوري . • 1 ـ الاهتمام بالبحث والدراسة عن دور المعلومات المحاسبية في تقييم الأداء البيئي .

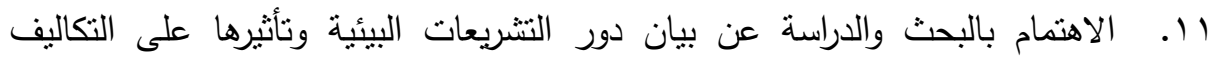




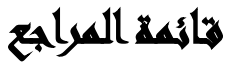

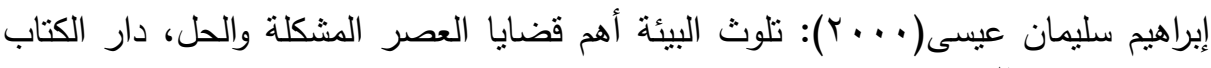
الحديث

ايمان محمد محمود البنا(1) ب ب): منخفض نوشكى دراسة فى الجيومورفولوجيا التطبيقية

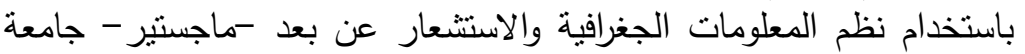
بنها - كلية الاداب - الجغرافيا

رجاء محمود أبو علام(991 (1)): مناهج البحث فى العلوم النفسية والتربوية، القاهرة، دار النشر

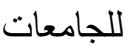

رشدى سعيد(ب99 1): نهر النيل، دار الهلال، الطبعة الثانية رشدى سعيد(ب991 (199): نهر النيل، دار الهلال، الطبعة الثانية، القاهرة.

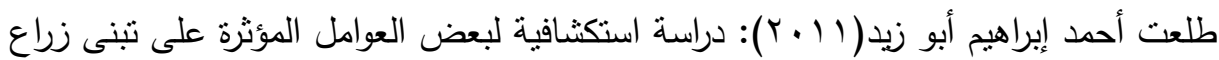

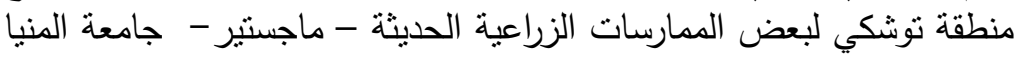

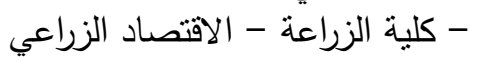

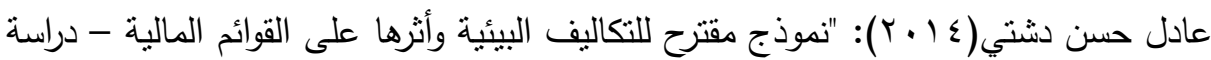

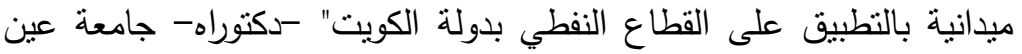

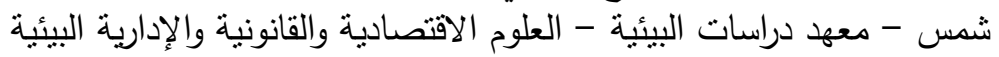

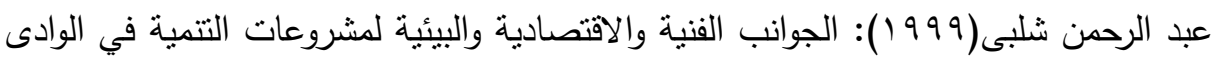
الجديد، مجلة طنطا للبيئة، عدد خاص عن نوشكى، العدد الخامس

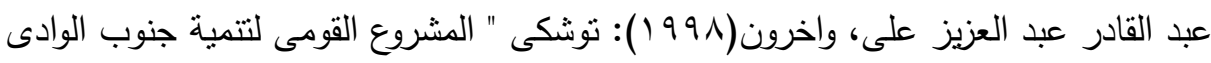

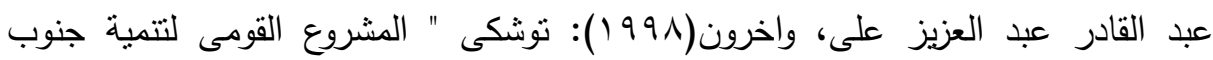
الوادى" مطبعة جامعة طنط واخرون

الكود المصري للموارد المائية واعمال الري - ج •م •ع وزارة الموارد المائية - المركز القومي

$$
\text { لبحوث المياه }
$$

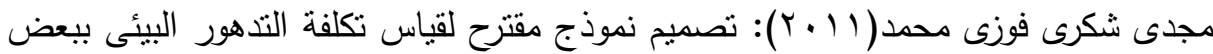

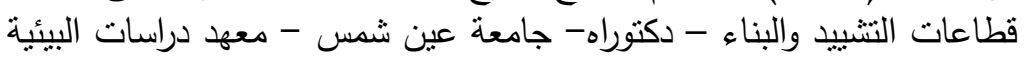

- الاقتصاد والقانون والتتمية الادارية البيئية

$$
\text { المجلد الثاني والثالثون، مارس } 17 \text { ـ ب }
$$




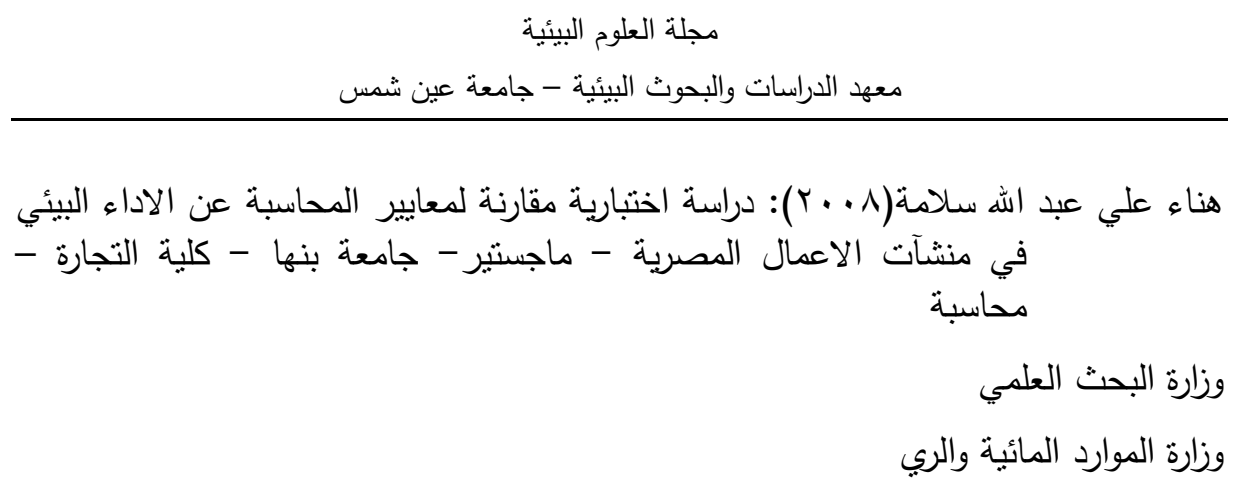

A study group for developing a system for environmental accounting, developing an environmental accounting system, environmental agency, Japan, 2000.6

Reyes, M.F., Environmental Management Accounting : Putting the right Numbers in Sustainable Projects , EMAN- AP,2002, P.1.

Old Gate, M.W., A Perspective of Environmental Pollution, (Cambridge: Cambridge University Press، ،

Lomborg, Bjorn, The Skeptical Environmentalist, Cambridge University Press , 2001،

http://www.infotechaccountants.com/forums 20-09-2007

http://www.hrm-group.com/vb/showthread.php?t= ‘27/8/2008، 
طارق عبد العال وآخرون

\title{
A PROPOSED MODEL FOR MEASURING COST AND BENEFIT IN WATER INSTITUTIONS TO EVALUATE THE ENVIRONMENTAL PERFORMANCE AN APPLIED STUDY ON TOSHKA PROJECT
}

Hammad, T. A. ${ }^{(1)}$; Soliman, E. M. ${ }^{(2)}$; Abou Zaid, M. A. ${ }^{(3)}$ and Hassanin, M. S. M.

1) Faculty of Commerce, Ain Shams University 2) Institute of Environmental Studies \& Research Ain Shams University 3) Minister of Water Resources \& Irrigation

\begin{abstract}
The environment kept its miraculous balance due to God's power till man, intentionally or non-intentionally, started to corrupt God's creation. This led to a huge problem, namely damaging the environment. Hence, the researcher decided to study and analyze costs, environmental returns of water industrial facilities of Toshka project of agricultural expansion under the title " A proposed Model to Measure Cost \& Return in Water Facilities with the aim of Assessing Environmental Performance- Applied Study on Toshka Project" .

This is due to the importance quality of accounting information for decision-making and conducting a research study of the opinions of a sample of those responsible for industrial facilities of Toshka Project. For the theoretical part of the studyk, light was shed on care of these facilities of environmental issues and nature of environmental costs borne by these facilities. The researcher also examined concept and nature of environmental costs and means of approaching them. As for the applied part, it is the research study and building a measurement model of cost \& return. Through a questionnaire form distributed on those working at industrial facilities at Toshka Project, results and
\end{abstract}

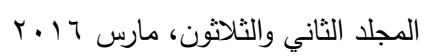


recommendations to achieve goals of the research were attained, the most important of which are:

\section{Firstly, Results:}

- There is no moral relationship of statistically significance between rationalizing costs in water facilities and the results of the environmental performance of these facilities.

- There is no moral- relationship of statistically significance between cost rationalization, revenue of water facilities \& the amount of environmental pollution.

- There is no moral relationship of statistically significance among the results of suggested model for measuring the cost \& revenue of water facilities \& rationalizing environmental performance of Toshka Project.

\section{Secondly: Recommendations:}

- Paying attention to laying out qualified cadres in the accountant units \& operational ones related to environment.

- Activating the laws that make the facilities conform to their responsibilities towards the environment \& paying attention to research \& study for indicating the role of environmental legislations $\&$ their effects on environmental costs.

- Paying attention to evaluation as a tool for improving the facilities performance periodically as well as research and study of accountancy information in evaluating environmental performance . 